\title{
A New Quantitative Model of Total Endolymph Flow in the System of Semicircular Ducts
}

\author{
M. Muller $†$ and J. H. G. Verhagen $\ddagger$
}

$\dagger$ Department of Experimental Animal Morphology and Cell Biology, and $\ddagger$ Department of Theoretical Production Ecology, Agricultural University, Marijkeweg 40, 6709 PG Wageningen, The Netherlands

(Received 19 March 1987, and in revised form 25 May 1988)

1. A new concept of endolymph flow in the vertebrate vestibular system is presented. This approach describes quantitatively the flow in the entire system of three semicircular ducts interconnected by the utriculus and the crus commune. This approach is quite distinct from the classical theory in which the labyrinth is generally conceived to consist of three separate duct circuits.

2 . The present approach shows the following set of distinct differences to the classical view:

(a) In a labyrinth composed of three ducts perpendicular to each other the flow is non-zero in the other ducts when the labyrinth is rotated in the plane of a particular duct.

(b) In a labyrinth with two equal ducts and with the duct planes under $\approx 73^{\circ}$ the flow in one duct is zero when the rotation takes place in the plane of the other duct. Previous measurements of duct angles reflect this value surprisingly well.

An obtuse or sharp angle between duct planes can lead to better performance of a particular labyrinth because the "external impulses" in the different ducts may amplify or compensate each other.

(c) The behaviour of the flow in the entire labyrinth is a non-linear function of direction or rotation (cf. points (d), (e)).

(d) Six time constants for the entire labyrinth can be distinguished (three long, three short); the flow in a particular duct is composed of six terms with these time constants. The composition of this flow and thus the relative importance of the terms depends on the positioning of the labyrinth with respect to the rotation vector.

(e) The time constants also depend, for different labyrinths, on a shared influence of the dimensions of the ducts and the elastic properties of all three cupulae.

(f) The forces in a particular duct depend also on the amount of motion the fluid will acquire in the other ducts.

(g) The sensitivity of a particular duct depends also on the dimensions of the other parts in the vestibular system.

3. Equations for a system consisting of two ducts and for the classical single duct system are also given. Both systems are special cases of the three-duct system. The single duct equations are equivalent with equations given by Oman (1980) and Oman et al. (1987) which include the contribution of a wide utriculus.

4. The present theory of endolymph flow is mainly supported by the outcome of previously performed experiments concerning time constants and rotation of human subjects in different planes. Measurements of relative dimensions of ducts, utriculus and crus commune are in accordance with considerations about sensitivity of the labyrinth which follow from our theory. However, additional evidence to verify our theory is needed. 


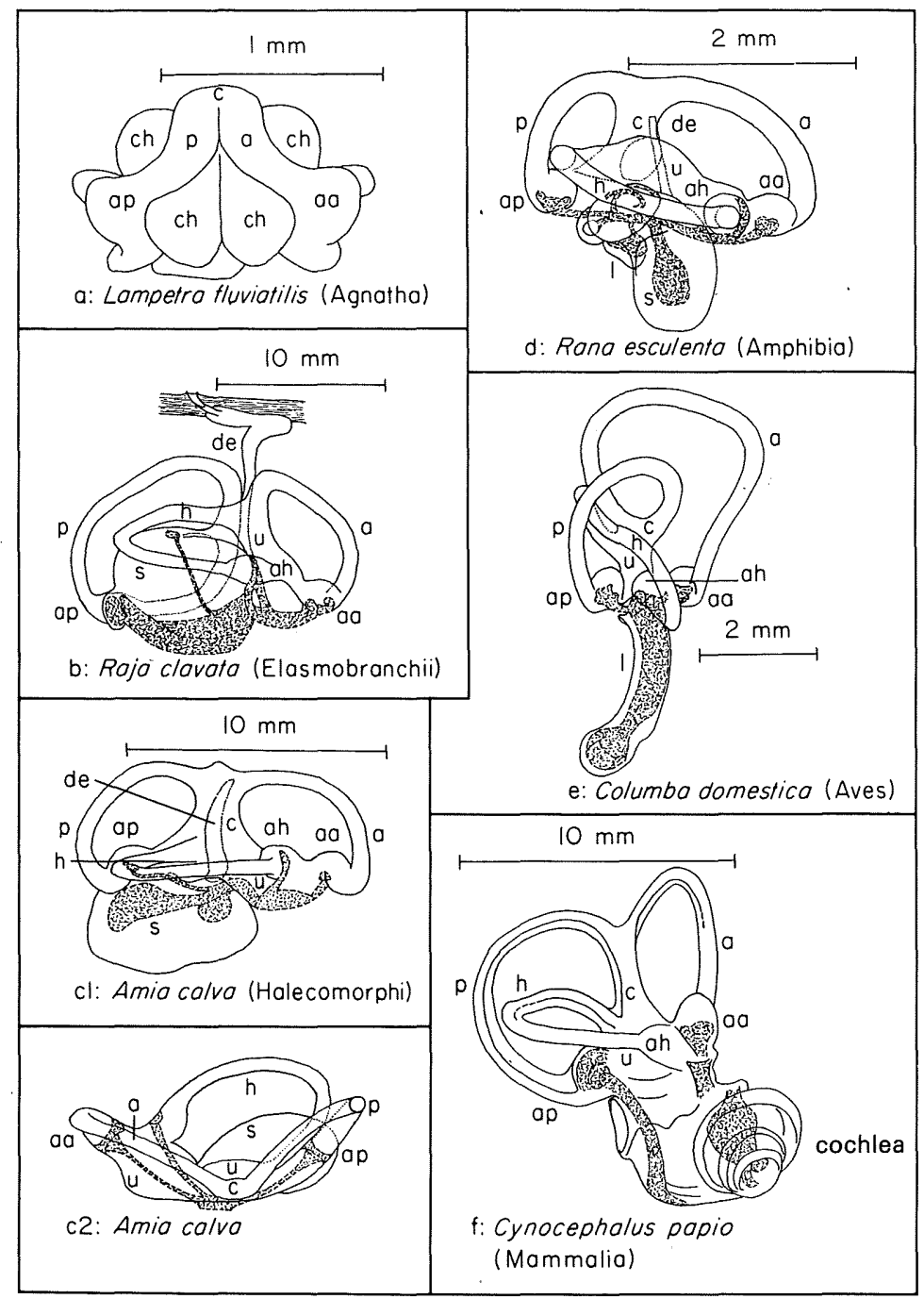

FIG. 1. Vertebrate labyrinth types; right side, from lateral unless otherwise indicated: $a$ : river lamprey, Lampetra fluviatilis (L.) (Agnatha, Petromyzoniformes), after De Burlet \& Versteegh (1930); $b$ : thornback ray, Raja clavata L. (Elasmobranchii), after Retzius (1881); c: bowfin, Amia calva L. (Halecomorphi), after Retzius. $c 1$ : from lateral, $c 2$ : from dorsal; $d$ : green frog, Rana esculenta L. (Amphibia, Salientia), after Retzius; $e$ : pigeon, Columba domestica (Aves), after Retzius; $f$ : yellow-faced baboon, Cynocephalus papio (Mammalia, Primates), after A. A. Gray (1907). Abbreviations: $a=$ anterior duct, $a a=$ ampulla anterior, $a h=$ ampulla horizontalis, $a p=$ ampulla posterior, $c=$ crus commune, $c h=$ ciliated chambers, $d e=$ ductus endolymphaticus, $h=$ horizontal duct, $l=$ lagena, $p=$ posterior duct, $s=$ sacculus, $u=$ utriculus.

Note the oblique angle (ca. $120^{\circ}$ ) between anterior and posterior duct in picture $c 2$, the non-planarity of some ducts, the separate posterior duct in the Ray's labyrinth (picture $b$ ), the relatively big crosssectional area of the crus commune and the perilymphatic canals in picture $f$. 


\section{Introduction}

The study of the mechanics of the semicircular ducts is a classical example of the application of physical laws to a biological system. Extensive reviews are given in for example de Burlet (1931; morphology), O. Gray (1951, 1955; phylogeny), van Egmond et al. (1952; physiology), ten Kate (1969; biophysics), Dohlman (1980; function of cupula) and Wilson \& Melvill Jones (1979; general information). All the preceding physical approaches started from the assumption of a single closed duct filled with endolymph (cf. De Vries, 1956), often a circular ring with at the sensor site an elastic element: the cupula. This system behaves as a torsion pendulum and can be described by an overdamped second order equation of motion. From this equation two time constants can be derived (van Egmond et al., 1949). The corresponding frequency response of the duct shows that it acts as an angular velocity transducer with a bandwidth determined by the time constants (Mayne, 1950; Melvill Jones \& Milsum, 1971). Simonovitch (1966), Van Buskirk (1977), Oman \& Young (1972), Oman (1980) and Oman et al. (1987) have extended the torsion pendulum model, also considering the influence of a wide utriculus and an elliptical cross section of the ducts.

The three-dimensional system has been treated previously as a combination of three separate circuits "almost" perpendicularly positioned to each other (cf. e.g. Valentinuzzi, 1967).

The present approach describes the flow in the entire labyrinth i.e. in the system formed by the interconnection of all three semicircular ducts with the common crus and the utriculus. It will be shown that this concept reveals rather large differences from previous mechanical descriptions, viz. non-linear behaviour of the flow as a function of direction of rotation, a set of six time constants with influence on the flow in each duct, an influence of the size of utriculus, crus commune and the other ducts on the sensitivity of a particular duct, and a shared influence of the elastic forces of the three cupulae upon the flow inside the system.

Retzius (1881), De Burlet (1931), A. A. Gray (1907), O. Gray (1951), Werner (1960) and Ramprashad et al. (1986) gave an extensive comparative description of labyrinth shapes. Although some of these references are rather old these descriptions are considered quite valid. Concerning phylogeny we follow mainly O. Gray (1951). In Agnatha (jawless fishes) a two-duct labyrinth exists with a rather unusual shape. In Myxine (hagfish) the two ducts, each with an ampulla, form a single ring. In the Petromyzoniformes (lampreys) the two ducts meet in a common part, as in a crus commune. At the point of their confluence a valve-like organ (spindle organ) is present (Löwenstein et al., 1968).

In Elasmobranchii (sharks and relatives) the third (i.e. horizontal) duct is found in a highly derived form (O. Gray, 1951; Werner, 1960). It appears to be closely connected to the anterior vertical duct. The posterior duct in this group is rather separate.

In Teleostei (bony fishes) and higher vertebrates we find the well-known general labyrinth shape (with regard to the semicircular ducts) although there are many modifications concerning shape, diameter, duct planes and connections between ducts.

The connection of the horizontal duct with the common crus (point $\mathrm{A}$ in the model) is subject to considerable variations; for this reason we chose points $B$ and $C$ in our model for the solution of the eqn of continuity. Inside the common crus the flow then becomes more complex, but with our theory it can still be solved for all cases. Also, labyrinths with highly modified connections, for example found in birds, (Fig. 1e) can be treated with our theory. 
When the ducts are mutually perpendicular and rotation takes place in the plane of one of the ducts, flow may also occur in the other two ducts.

In this paper the physical essentials of this new flow model are given together with experimental evidence from other publications supporting the validity of the present approach. A detailed mathematical treatment will be published separately (Muller \& Verhagen, 1988).

\section{Simplifications}

Figure 1 shows a sample of the enormous variety in existing vertebrate labyrinth types (cf. Retzius, 1881; De Burlet, 1931; A. A. Gray, 1907; O. Gray, 1951, 1955; for extensive descriptions). From this picture and the referred literature it is evident that the angle between the planes of the different ducts in different species may seriously deviate from the $90^{\circ}$ value and also that the duct circuits are not always planar. We chose as a base for our model the common mammalian type, also because of its significance for the human system. In Fig. 2 is shown how the duct system

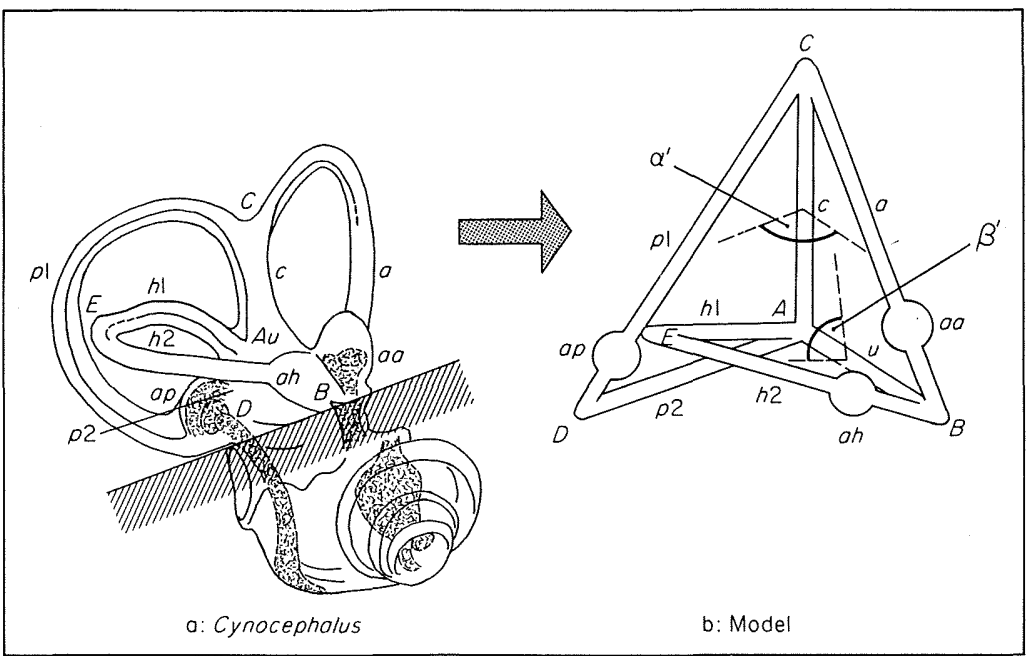

FIG. 2. Derivation of our model-labyrinth with triangular geometry from a real system (Cynocephalus). The horizontal and posterior duct circuits are both connected to the anterior duct circuit. No direct interconnection between horizontal and posterior ducts exists. For reasons of clarity we have displayed the model labyrinth with equal cross-sectional areas. Also in the Cynocephalus labyrinth $p_{2}$ and $u$ are rather small. Figure 1, however, demonstrates that the lengths as well as the cross-sectional areas of the different parts of the labyrinth may vary from species to species. All these parameters can be varied in our model (cf. Table 1). In this and the following Figures the spherical shape of the ampullae is not included in the model and only chosen to point out the positions of these labyrinth parts (see also 5.2.4).

We chose for reasons of simplicity a triangular geometry for the duct system; when other forms are chosen the geometrical description of the labyrinth demands more parameters. For model construction it is recommended to reduce the amount of parameters as much as possible.

Abbreviations: $a=$ anterior duct; $c=$ crus commune; $h_{1}, h_{2}=$ parts of horizontal duct; $p_{1}, p_{2}=$ parts of posterior duct (and utriculus); $u=$ utriculus; $a a, a p, a h=$ ampullae; $A, B, C, D$ and $E$ : points of connection between ducts, $\alpha^{\prime}, \beta^{\prime}=$ interior angles between duct planes. 
chosen by us can be derived from a real labyrinth. The angles between the anterior and the posterior duct $\left(\alpha^{\prime}\right)$ and between the anterior and the horizontal duct $\left(\beta^{\prime}\right)$ are allowed to vary between 0 and $180^{\circ}$ in order to simulate different labyrinths. The lengths and the diameters of the ducts also can be varied. The elastic properties of the three cupulae have been chosen identically (this condition may easily be relaxed). The labyrinth is allowed to rotate around an origin by a vector $\omega$ in all possible directions at a particular position in space. For reasons of simplicity we have chosen a triangular geometry for the ducts (Fig. 2). The choice of other shapes and connections between the ducts does not give rise to fundamental physical problems (cf. Muller \& Verhagen, 1988).

\section{The Model}

\subsection{GEOMETRY}

The canal system representing the labyrinth has been defined by the co-ordinates of points $\mathrm{A}$ to $\mathrm{E}$ (Fig. 3 ) in a flat $(x, z)$ plane. The triangle $\mathrm{ABC}$ represents the circuit formed by the anterior duct $(a)$, the crus commune $(c)$ and the utriculus $(u)$. The triangle AEB represents the horizontal duct $\left(h=h_{1}+h_{2}\right)$, connected to the utriculus. The triangle ADC is formed by the posterior duct $\left(p=p_{1}+p_{2}\right)$ connected to the common crus. The latter definition does not fully cover the anatomical definition since $p_{2}$ is in fact a part of the utriculus. The chosen definition, however, facilitates the physical analysis for reasons of symmetry. The position of the cupulae is chosen as indicated in Fig. 3.

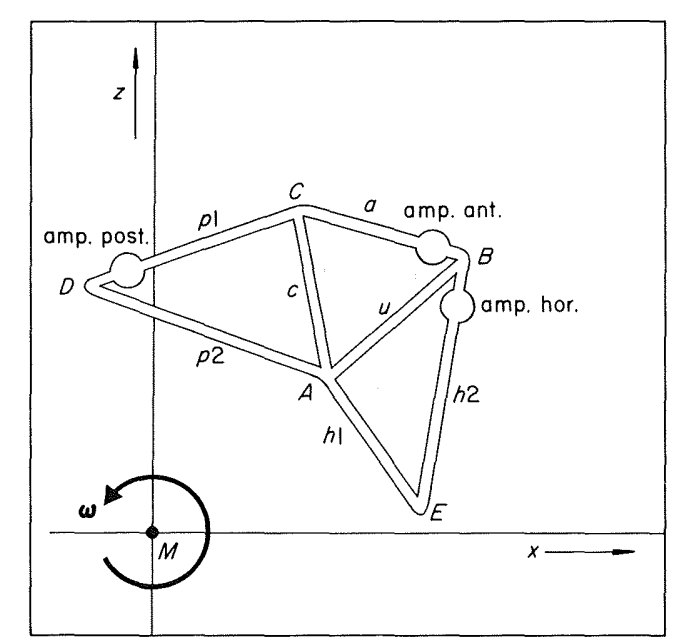

FIG. 3. Definition of the labyrinth circuit in a flat $(x, z)$-plane. The planes $A E B$ and $A C D$ can be rotated around $u$ and $c$ respectively in order to form a three-dimensional labyrinth. This labyrinth is rotated by a vector $\omega$ along the $y$-axis in $M$. The plane $A B C$ can be tilted with respect to a $(x, z)$-plane.

Abbreviations: $x, y, z=$ co-ordinates in space (the $y$-axis is perpendicular to the $x$-axis and $z$-axis); $\omega=$ rotation vector; $M=$ origin of earth-bound frame; other symbols are the same as in Fig. 1. 
The posterior duct $(\mathrm{ADC})$ can be positioned by rotation around the line $\mathrm{AC}$ with respect to the anterior duct $(\mathrm{ABC})$ by an angle $\alpha$ (Fig. 4); analogously the horizontal duct $(\mathrm{AEB})$ can be positioned with respect to the duct $(\mathrm{ABC})$ by an angle $\beta$. The whole labyrinth can be positioned in space by translation in the $(x, z)$ plane and rotation of this plane around the $x$-axis with an angle $\mu$. Choosing a particular $\alpha, \beta$ and $\mu$ results in a labyrinth shape in a $3 \mathrm{D}$-space. Table 1 lists all parameters that describe the labyrinth in space.

\subsection{INPUT SIGNAL FOR THE LABYRINTH SYSTEM}

In order to simplify our analysis we have rotated the labyrinth according to the classical cupulometry experiment (Groen \& Jongkees, 1948; van Egmond et al. 1948; Hulk \& Jongkees; 1948), i.e. a rotation of a relatively long duration was applied until the fluid did not move with respect to the labyrinth wall. Then the labyrinth was suddenly stopped $(t=0)$. The fluid still has an initial impulse (momentum) and moves according to the eqn of motion:

$$
M \ddot{x}+F \dot{x}+S x=0
$$

in which $M$ ("mass") is the mass of the endolymph, $F$ ("friction") is a factor describing the friction within the endolymph, $S$ ("spring constant") is a factor denoting the elasticity in the system due to the cupula and $\ddot{x}, \dot{x}, x$ are respectively the endolymph acceleration, velocity and displacement with respect to the wall of a duct.

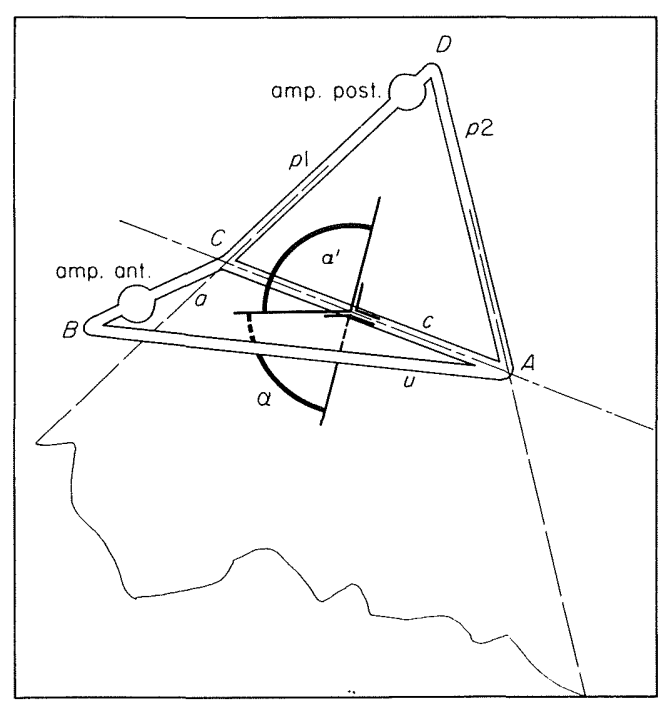

FIG. 4. Definition of angles between duct planes. The posterior duct (i.e. $A C D$ can be positioned with respect to the anterior duct circuit $(A B C)$ by an angle $\alpha$ (or $\alpha^{\prime}$ ). Analogously the horizontal duct $(A E B)$ is positioned with respect to the anterior duct using an angle $\beta$ (or $\beta^{\prime}$ ). For abbreviations cf. Fig. 1. 
ENDOLYMPH FLOW IN THE SEMICIRCULAR DUCTS. I

TABLE 1

Parameters, describing labyrinth model in space (cf. Figs 2 and 3)

\begin{tabular}{ccccc}
\hline Co-ordinates & $\begin{array}{c}\text { Lengths of } \\
\text { ducts }\end{array}$ & $\begin{array}{c}\text { Cross-sectional } \\
\text { areas of } \\
\text { ducts }\end{array}$ & Angles \\
\hline$x_{A} \quad z_{A}$ & $a$ & $A_{a}$ & $\alpha(A D C)$ \\
$x_{B}$ & $z_{B}$ & $u$ & $A_{u}$ & $\beta(A E B)$ \\
$x_{C}$ & $z_{C}$ & $c$ & $A_{c}$ & \\
$x_{D}$ & $z_{D}$ & $h=h_{1}+h_{2}$ & $A_{h}$ & \\
$x_{E}$ & $z_{E}$ & $p=p_{1}+p_{2}$ & $A_{p}$ & \\
\hline
\end{tabular}

$x_{A}-x_{E}$ and $z_{A}-z_{E}$ are the co-ordinates that define the shape of the labyrinth in a flat $(x, z)$-plane. The lengths of the ducts follow from the co-ordinates. The duct circuit $A D C$ (posterior duct) is positioned with respect to duct circuit $A B C$ (the anterior duct) at an angle $\alpha$. Duct circuit $A E B$ (horizontal duct) is positioned with respect to $A B C$ at an angle $\beta$. The whole, three-dimensionally defined, labyrinth can be rotated and translated in the $A B C$-plane. The latter plane can be tilted with respect to the rotation vector $\omega$ by an angle $\mu$. The result is a 3-dimensional labyrinth in space, rotating around the $y$-axis of the $\{x, y, z\}$ co-ordinate system.

For a single duct circuit the time constants of the equation of motion are:

$T 1=F / S$ (long time constant) and $T 2=M / F$ (short time constant)

However, for a system composed of three interconnected ducts such simple formulae for the time constants cannot be given (see below, formula 3.5.2).

The behaviour of the system is yet determined by the initial conditions: $x=0$ at $t=0$ and the values of the impulses in the different ducts at $t=0$ (note that these conditions do not include friction) and the time constants (in which also the influence of friction is expressed).

There is a considerable amount of literature in which this experiment has been carried out and discussed. Our model can thus be checked by the outcome of these previously performed experiments.

\subsection{CONTINUITY EQUATION}

In the connections $B$ and $C$ between the ducts the equation of continuity of fluid has to be applied. The two continuity equations become:

$$
\begin{aligned}
& \dot{x}_{u} A_{u}=\dot{x}_{a} A_{a}-\dot{x}_{h} A_{h} \quad \text { (Fig. 3, point } B \text { ) } \\
& \dot{x}_{c} A_{c}=\dot{x}_{a} A_{a}-\dot{x}_{p} A_{p} \quad \text { (Fig. 3, point } C \text { ) }
\end{aligned}
$$

In words this means that the sum of the flow rates of the ducts is zero.

\subsection{IMPULSE EQUATIONS}

The initial impulse $\left(\mathbf{I}_{e x}\right)$, exclusively resulting from rotation of a part of a duct (the "external" impulse) can be determined by the equation:

$$
\mathbf{I}_{s e x}=\rho \cdot \boldsymbol{\omega}_{s} * \int_{0}^{l_{s}} A_{s} \cdot \mathbf{h}_{s} \cdot d s \quad(t=0)
$$


in which $l_{s}$ is the length of the duct part, $\rho$ is endolymph density, $\omega_{s}$ is the component of $\boldsymbol{\omega}$ perpendicular to the duct and $\mathbf{h}_{s}$ is the distance vector between $\boldsymbol{\omega}$ and the duct (see Muller \& Verhagen, 1988 for derivation).

The real impulse (I) in a duct (i.e. the real amount of motion the fluid in that duct possesses) is not equal to this external impulse but is also influenced by the external impulses in the other ducts. To determine the real impulse we first consider the pressure differences between e.g. $A$ and $C$. This pressure difference is equal along paths $p$ and $c$. This results in an equation for the impulses:

$$
\left(\mathbf{I}_{p}-\mathbf{I}_{p e x}\right) / A_{p}=\left(\mathbf{I}_{c}-\mathbf{I}_{c e x}\right) / A_{c}=\left(p_{C}-p_{A}\right) . \Delta t
$$

in which $p$ is the pressure due to endolymph movement in a connection between ducts (indicated by the subscript; see Muller \& Verhagen, 1988 for derivation).

Analogously, consideration of the pressure difference between points $A$ and $B$ yields:

$$
\left(\mathbf{I}_{h}-\mathbf{I}_{\text {hex }}\right) / A_{h}=\left(\mathbf{I}_{u}-\mathbf{I}_{\text {uex }}\right) / A_{u}=\left(p_{A}-p_{B}\right) . \Delta t
$$

Addition of (3.4.2) and (3.4.3), also considering the pressure difference between $B$ and $C$ gives four possibilities, e.g:

$$
-\left(\mathbf{I}_{a}-\mathbf{I}_{a e x}\right) / A_{a}=\left(\mathbf{I}_{p}-\mathbf{I}_{p e x}\right) / A_{p}+\left(\mathbf{I}_{h}-\mathbf{I}_{h e x}\right) / A_{h}=\left(p_{C}-p_{B}\right) . \Delta t
$$

The impulse eqns (3.4.2), (3.4.3) and (3.4.4) together with the equations of continuity $(3.3 .1 \mathrm{a}, \mathrm{b})$ form a system of five equations with five unknown variables $\dot{x}_{a}(0), \dot{x}_{p}(0), \dot{x}_{h}(0), \dot{x}_{c}(0), \dot{x}_{u}(0)$.

In matrix notation these five equations become:

$$
\left[\begin{array}{ccccc}
0 & m_{p} / A_{p} & 0 & -m_{c} / A_{c} & 0 \\
0 & 0 & m_{h} / A_{h} & 0 & -m_{u} / A_{u} \\
m_{a} / A_{a} & m_{p} / A_{p} & m_{h} / A_{h} & 0 & 0 \\
-A_{a} & 0 & A_{h} & 0 & A_{u} \\
-A_{a} & A_{p} & 0 & A_{c} & 0
\end{array}\right]\left[\begin{array}{c}
\dot{x}_{a}(0) \\
\dot{x_{p}}(0) \\
\dot{x_{h}}(0) \\
\dot{\dot{x}_{c}}(0) \\
\dot{x_{u}}(0)
\end{array}\right]=\left[\begin{array}{c}
\left(\mathbf{I}_{\text {pex }} / A_{p}-\mathbf{I}_{c e x} / A_{c}\right) \\
\left(\mathbf{I}_{\text {hex }} / A_{h}-\mathbf{I}_{\text {uex }} / A_{u}\right) \\
\left(\mathbf{I}_{a e x} / A_{a}+\mathbf{I}_{p e x} / A_{p}+\mathbf{I}_{h e x} / A_{h}\right) \\
0 \\
0
\end{array}\right]
$$

This system can be solved by conventional procedures. Yet the initial velocities in all the ducts of the system are known. With these initial conditions the equation of motion for the entire labyrinth can be solved.

\subsection{EQUATION OF MOTION}

For each duct $(a, p$ and $h)$ an equation of motion of the type (3.2.1) can be formulated. The same holds for crus commune $(c)$ and utriculus $(u)$. The latter two equations lack the term with $S$ because there is no cupula in these labyrinth parts. These equations of motion can be combined, in a way comparable with that for the impulses, according to pressure conditions in the joints of the ducts. For example: 
for ducts $h$ and $u$ the equation of motion becomes:

$$
\left(M_{h}, \ddot{x}_{h}+F_{h} \cdot \dot{x}_{h}+S_{h} \cdot x_{h}\right) / A_{h}=\left(M_{u} \cdot \ddot{x}_{u}+F_{u} \cdot \dot{x}_{u}\right) / A_{u}=\left(p_{A}-p_{B}\right)
$$

Combination of these equations with the equations of continuity $(3.3 .1 \mathrm{a}, \mathrm{b})$ results in the following set of three simultaneous second order differential equations (ref. also Kuipers \& Timman, 1966):

$$
\left[\begin{array}{lll}
{[A 1]} & {[B 1]} & {[C 1]} \\
{[A 2]} & {[B 2]} & {[C 2]} \\
{[A 3]} & {[B 3]} & {[C 3]}
\end{array}\right]\left[\begin{array}{l}
X_{a} \\
X_{p} \\
X_{h}
\end{array}\right]=0
$$

in which $[A 1] \ldots[C 3]$ are (quadratic) constants, expressed in Cauchy's differential operator $D$ (comparable with a Laplace operator) and the dimensions and physical constants of the labyrinth (cf. Muller \& Verhagen, 1988 for detailed formulae) and $X$ is the endolymph displacement in the $D$-domain. This system of equations is equivalent with a sixth order differential equation describing the endolymph motion in the whole labyrinth. So, no separate (second order) equations for each duct exist, as was the case in the classical approach. Apart from the trivial solutions $x_{a}=x_{p}=$ $x_{h}=0$, the above system has a solution when the determinant of the left matrix equals zero. This gives rise to a characteristic equation (in $D$ ) of the 6 th degree. The solution has the form:

$$
\begin{aligned}
& x_{a}=\sum_{i=1}^{6} a_{i} \cdot \exp \left(-t / T_{i}\right) \\
& x_{p}=\sum_{i=1}^{6} b_{i} \cdot \exp \left(-t / T_{i}\right) \\
& x_{h}=\sum_{i=1}^{6} c_{i} \cdot \exp \left(-t / T_{i}\right)
\end{aligned}
$$

in which $a_{i}, b_{i}, c_{i}$ are constants and $T_{i}$ are the six time constants of the labyrinth. $x_{c}$ and $x_{u}$ follow from the equations of continuity $(3.3 .1 \mathrm{a}, \mathrm{b})$. The flow in each $d u c t$ is thus determined by all six time constants. The terms with these time constants may however be of different size in the respective ducts. So, a specific time constant may have a most important influence on the flow in a particular duct.

\subsection{COMPUTER SIMULATION}

For numerical calculation we have chosen the labyrinth shape drawn in Fig. 5. According to Oman \& Young (1972) and Van Buskirk (1977) a "duct ring" of a human labyrinth has a radius $(R)$ of $3 \cdot 0 \times 10^{-3}$ to $3 \cdot 2 \times 10^{-3} \mathrm{~m}$. The co-ordinates in Fig. 5 have been chosen in such a way that a triangular circuit (e.g. $A E B$ ) has about the same circumference. 


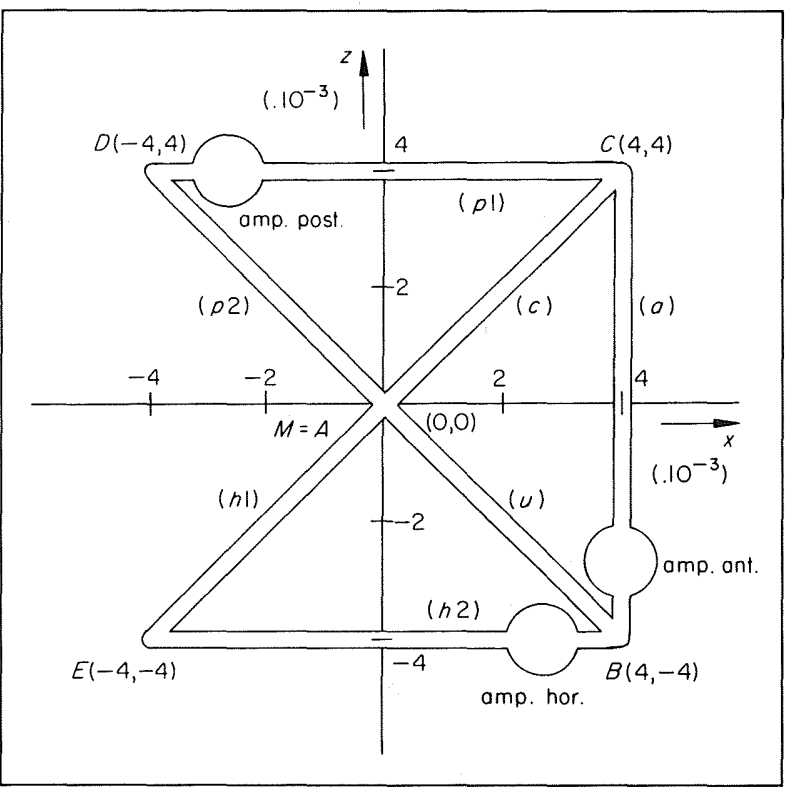

FIG. 5. Geometry of a labyrinth, chosen for digital computation. A single duct circuit (e.g. $A E B$ ) of this labyrinth should produce time constants comparable to the values found by Oman \& Young (1972) for a human labyrinth (horizontal duct). Dimensions in m. For abbreviations cf. Fig. 1.

The radii of ducts $a, p$ and $h$ have been chosen to be equal with a value of $1.75 \times 10^{-4} \mathrm{~m}$ (i.e. slightly bigger than the $r=1.5 \times 10^{-4} \mathrm{~m}$ given by Van Buskirk (1977) in order to match our choice of geometry with the time constants). The crus commune $(c)$ has been made wider by a factor of 1.93 . This factor we obtained by a regression analysis of the radii of 200 labyrinths of different species (details we will publish elsewhere). Similarly, the radius of the utriculus was chosen a factor 2.42 times $r_{a}$.

Choosing the physical constants $\eta=8 \times 10^{-4} \mathrm{~kg} /\left(\mathrm{m} . \mathrm{s}\right.$.) $\left(37^{\circ} \mathrm{C}\right.$; Steer, 1967$), \rho=$ $1000 \mathrm{~kg} / \mathrm{m}^{3}$ (Steer, 1967), $S=1.389 \times 10^{-5} \mathrm{~N} / \mathrm{m}$ (cf. also ten Kate, 1969; Grant \& Van Buskirk, 1976) results in time constants:

$$
T_{1}=20 \mathrm{sec}, \quad T_{2}=0.005 \mathrm{sec}
$$

according to values given by Oman \& Young (1972).

The value of $S$ is a calculated, not a measured, value. This particular value was merely chosen to fit the long time constant $T_{1}$ to a realistic order of magnitude. It is beyond the aim of this paper to derive an accurate value for $S$.

With the above values, the maximum endolymph displacement in duct $h$ becomes about $1-10 \mu \mathrm{ms}$. This corresponds rather well with values given by Oman (1980). Because Dohlman (1980) has argued that the utricular volume may be small (contrary to Oman, 1980) we have also made simulations with a relatively narrow utriculus $\left(r_{u}=1.4 \times 10^{-4} \mathrm{~m}\right)$. 


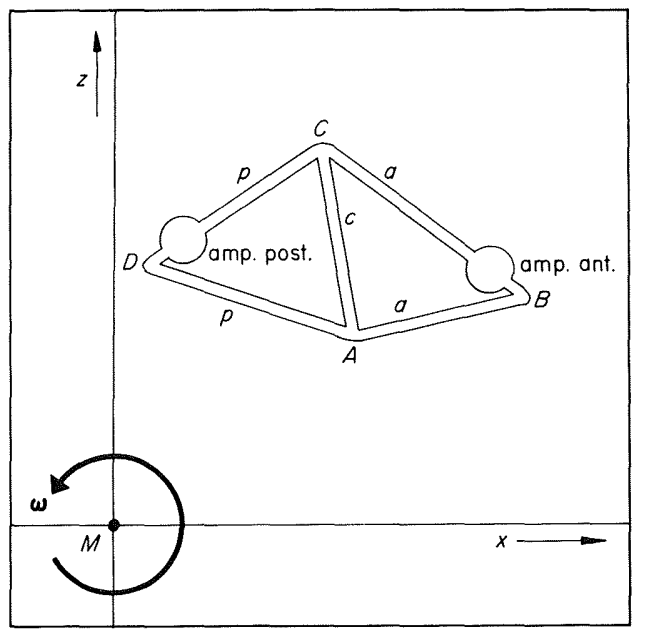

FIG. 6. Geometrical definition of a two-duct labyrinth. This figure is comparable with Fig. 3. Note that here three duct parts are distinguished (i.e. $a, c$ and $p$ ).

\section{Results of some Simple Calculations}

\subsection{TWO SEMICIRCULAR DUCTS}

The described general model for three semicircular ducts can be considerably simplified when only two ducts (e.g. $A B C$ and $A C D$ ) are considered. This enables not only the simulation of labyrinths of jawless fishes (Agnatha, Petromyzoniformes) but it is also attractive as a relatively simple "help-for-thinking". In this paragraph first the general equations for the two-duct labyrinth are given, followed by further simplifications for some special configurations. The notation is the same as in the preceding chapter.

\subsubsection{General equations}

The geometry of the two duct system is given in Fig. 6. Plane $A C D$ can be rotated with respect to $A B C$ by an angle $\alpha$. The rest of the geometry is analogous to section 3 .

The continuity equation becomes:

$$
\dot{x}_{c} A_{c}=\dot{x}_{a} A_{a}-\dot{x}_{p} A_{p}
$$

Relating the velocities in $(a)$ and $(p)$ by a (time-dependent) factor $k_{\alpha}$ as follows:

$$
\dot{x}_{p}=k_{\alpha} \dot{x}_{a}
$$

gives for the equation of continuity:

$$
\dot{x}_{c}=\dot{x}_{a}\left(A_{a}-k_{\alpha} A_{p}\right) / A_{c}
$$

The equations for the initial impulses become (analogous to eqns 3.4.2-3.4.4):

$$
\left(\mathbf{I}_{p}-\mathbf{I}_{p e x}\right) / A_{p}=\left(\mathbf{I}_{c}-\mathbf{I}_{c e x}\right) / A_{c}=-\left(\mathbf{I}_{a}-\mathbf{I}_{a e x}\right) / A_{a}=\left(p_{C}-p_{A}\right) . \Delta t
$$


The relations (4.1.1.3) are in fact two equations. They form, together with the equation of continuity, a system of three equations with three unknown variables $\dot{x}_{p}(0), \dot{x}_{c}(0), \dot{x}_{a}(0)$ :

$$
\left[\begin{array}{ccc}
0 & m_{p} / A_{p} & -m_{c} / A_{c} \\
m_{a} / A_{a} & m_{p} / A_{p} & 0 \\
-A_{a} & A_{p} & A_{c}
\end{array}\right]\left[\begin{array}{c}
\dot{x}_{a}(0) \\
\dot{x_{p}}(0) \\
\dot{x}_{c}(0)
\end{array}\right]=\left[\begin{array}{c}
\mathbf{I}_{p e x} / A_{p}-\mathbf{I}_{c e x} / A_{c} \\
\mathbf{I}_{p e x} / A_{p}+\mathbf{I}_{a e x} / A_{a} \\
0
\end{array}\right]
$$

The equation of motion yet leads to four time constants (see Muller \& Verhagen, 1988).

\subsubsection{Some examples}

In this paragraph it is assumed that $m_{p}=m_{a}=m$ and all cross-sectional areas are equal to $A$. Rotation takes place around point $A$ in plane $A B C$, so $\mathbf{I}_{c e x}=0$. From (4.1.1.4) it follows that:

$$
k_{\alpha}=\frac{\left(m+m_{c}\right) \cdot \mathbf{I}_{p e x}+m_{c} \cdot \mathbf{I}_{a e x}}{m_{c} \cdot \mathbf{I}_{p e x}+\left(m+m_{c}\right) \cdot \mathbf{I}_{a e x}}
$$

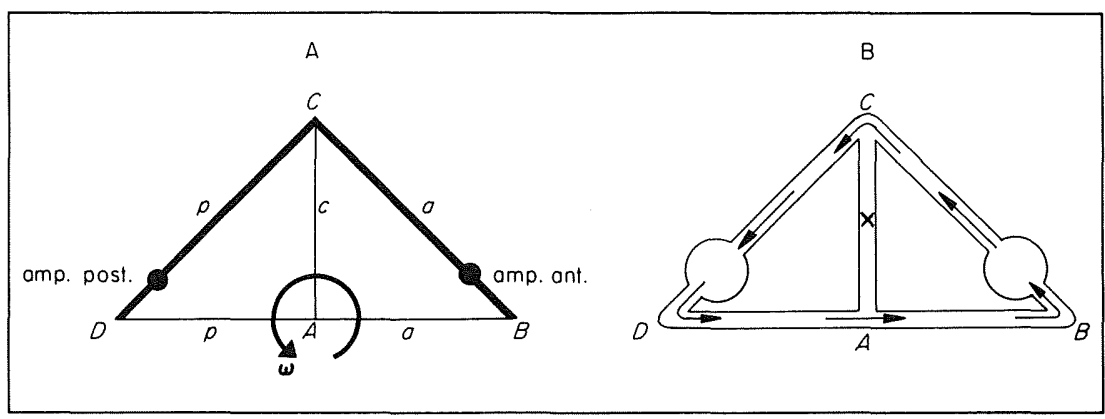

FIG. 7. Example 1. (A) Picture of external impulses. If this labyrinth is rotated in plane $A B C$ by $\omega$ around point $A$ external impulses occur in the ducts which are drawn bold. (B) Picture of flow. In the common crus $(A C)$ no flow exists. This is indicated by the $\times$ sign. The path of flow is indicated by arrows. Abbreviations as in Fig. 1. Further explanation in text (section 4.1.2).

\subsubsection{Example 1 (Fig. 7):}

$\alpha=0^{\circ}$ : the planes of the ducts are folded apart into the same plane, $\mathbf{I}_{p e x}=\mathbf{I}_{a e x}=\mathbf{I}$, so:

$$
k_{\alpha}=\frac{\left(m+m_{c}\right) \cdot \mathbf{I}+m_{c} \cdot \mathbf{I}}{m_{c} \cdot \mathbf{I}+\left(m+m_{c}\right) \cdot \mathbf{I}}=1,
$$

so $\dot{x}_{p}(0)=\dot{x}_{a}(0)$ and $\dot{x}_{c}(0)=0$.

In words: the flow occurs along the "periphery" i.e. ducts $a$ and $p$ behave as a single circuit. In the common crus no flow occurs.

A comparable flow (but with another magnitude) is obtained for any other $\alpha$ for which the projection of the ducts gives an equivalent picture as Fig. 7. 


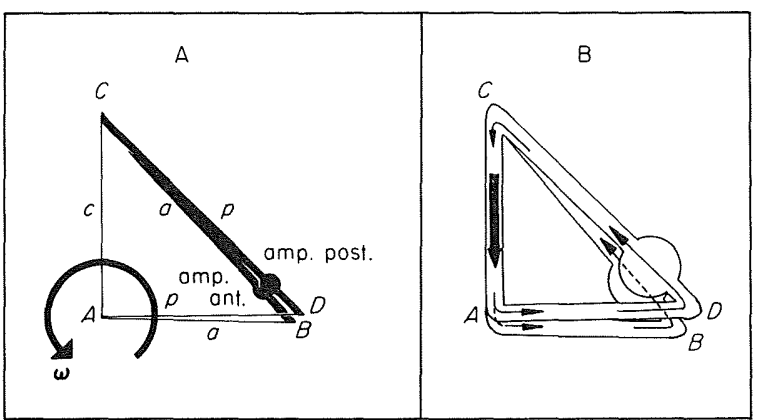

FIG. 8. Example 2. (A) External impulses. (B) Flow picture. This figure is comparable with Fig. 7. Further explanation in text (section 4.1.2).

\subsubsection{Example 2 (Fig. 8):}

$\alpha=180^{\circ}$ : the planes of the ducts are completely folded together, $\mathbf{I}_{\text {pex }}=-\mathbf{I}_{\text {aex }}$ so,

$$
k_{\alpha}=\frac{-\left(m+m_{c}\right) \cdot \mathbf{I}_{a e x}+m_{c} \cdot \mathbf{I}_{a e x}}{-m_{c} \cdot \mathbf{I}_{a e x}+\left(m+m_{c}\right) \cdot \mathbf{I}_{a e x}}=-1
$$

so $\dot{x}_{p}(0)=-\dot{x}_{a}(0)$ and $\dot{x}_{c}(0)=2 \cdot \dot{x}_{a}(0)$.

In words: in both ducts the endolymph streams towards the apex of the common crus. In the common crus the flow of the two ducts is added. Here also a comparable flow (with a different magnitude) is obtained for any other $\alpha$ for which the projection of the ducts gives an equivalent picture as Fig. 8.

\subsubsection{Example 3 (Fig. 9):}

$\alpha=90^{\circ}$, the planes of the two ducts are perpendicular to each other. $\mathbf{I}_{p e x}=0$

$$
k_{\alpha}=\frac{\mathbf{I}_{a e x} \cdot m_{c}}{\mathbf{I}_{\text {aex }} \cdot\left(m_{c}+m\right)}=\frac{m_{c}}{m_{c}+m}
$$

Thus, in this example, the endolymph flows also in duct $p$, despite the fact that this duct is perpendicular to the plane of rotation.

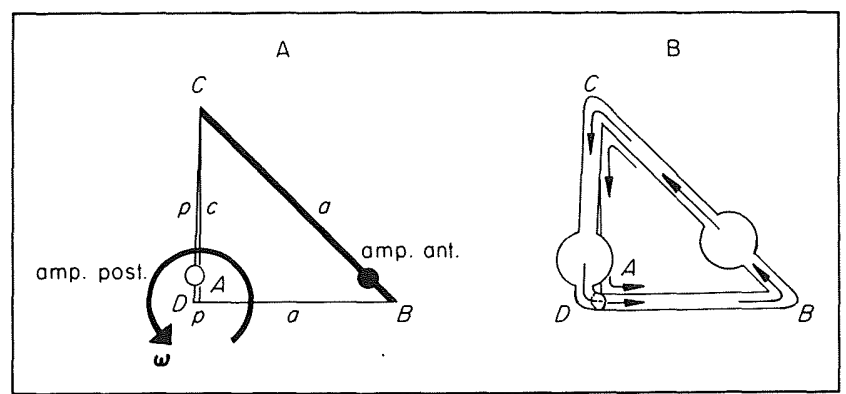

FIG. 9. Example 3. (A) External impulses. (B) Flow picture. This figure is comparable with Fig. 7. Further explanation in text (section 4.1.2). 
If e.g. $m_{c}=1$ it follows from Fig. 9 that $m=1+\sqrt{2}$ and $k_{\alpha} \approx 0 \cdot 29$

$$
\rightarrow\left\{\begin{array}{l}
\dot{x}_{p}(0) \approx 0 \cdot 29 \dot{x}_{a}(0) \\
\dot{x}_{c}(0) \approx\left(1-k_{\alpha}\right), \dot{x}_{a}(0) \approx 0 \cdot 71 \cdot \dot{x}_{a}(0)
\end{array}\right.
$$

So a considerable flow exists in the posterior duct.

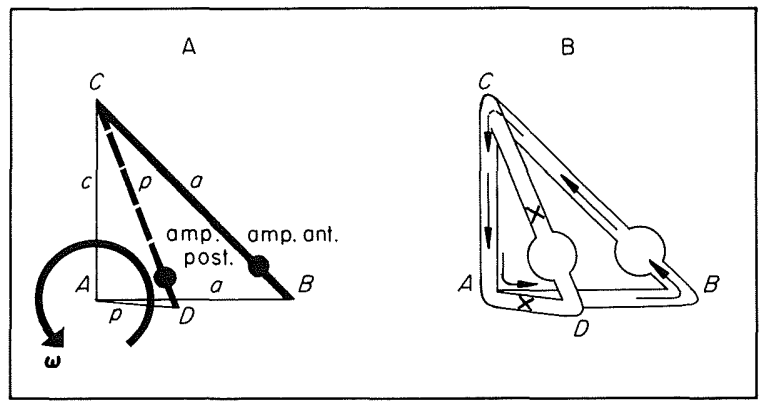

Fig. 10. Example 4. (A) External impulses. (B) Flow picture. This figure is comparable with Fig. 7. Further explanation in text (section 4.1.2).

\subsubsection{Example 4 (Fig. 10):}

In this example we will search for the angle $\alpha$ between the ducts for which there is no flow in $p$. Therefore we state $\dot{x}_{p}=0 \rightarrow k_{\alpha}=0$

$$
\rightarrow \frac{\left(m+m_{c}\right) \cdot \mathbf{I}_{p e x}+m_{c} \cdot \mathbf{I}_{a e x}}{m_{c} \cdot \mathbf{I}_{p e x}+\left(m+m_{c}\right) \cdot \mathbf{I}_{a e x}}=0
$$

A condition is that the denominator may not become zero, so:

$$
\left(\mathbf{I}_{p e x} / \mathbf{I}_{a e x}\right) \neq-\left(m+m_{c}\right) / m_{c} .
$$

Equation (4.1.2.4) is fulfilled if:

$$
\left(\mathbf{I}_{p e x} / \mathbf{I}_{a e x}\right)=-m_{c} /\left(m+m_{c}\right) .
$$

For $m_{c}=1$ and $m=1+\sqrt{2}$ it follows that $\mathbf{I}_{\text {pex }} \approx-0 \cdot 29$. $\mathbf{I}_{\text {aex }}$. Substitution of this relation in formula (3.4.1) yields $\omega_{p}=-0 \cdot 29 . \omega_{a}$ or $\omega \cdot \cos (\alpha)=-0 \cdot 29 \cdot \omega$. This is achieved for an angle $\alpha$ of ca. $107^{\circ}$. Thus the sharp angle $\left(\alpha^{\prime}\right)$ between the ducts is ca. $73^{\circ}$ (see also section 5.1.1).

\subsection{ONE (SEMI)-CIRCULAR DUCT (HERE TRIANGULAR)}

This is the classical approach, which is a special case of the theory presented here. The geometry is shown in Fig. 11. 


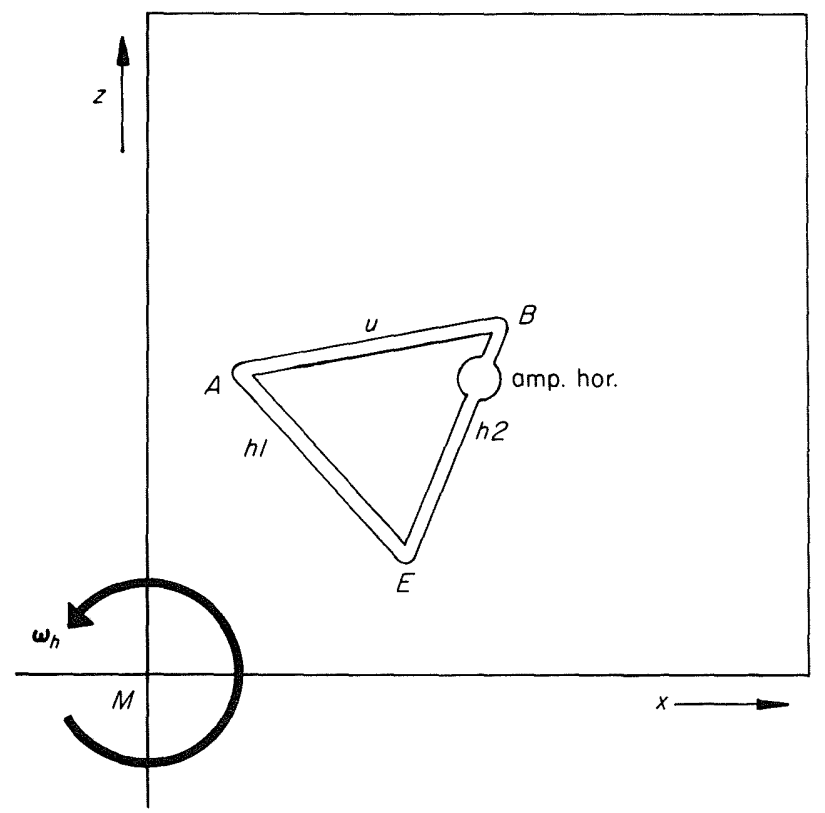

FIG. 11. Geometrical definition of a labyrinth, forming a single duct circuit. This labyrinth represents the classical approach (cf. van Egmond et al. 1949; Oman et al., 1987). Abbreviations: see Fig. 1.

The matrix (3.4.5) for the initial conditions can be simplified to:

$$
\left[\begin{array}{cc}
m_{h} / A_{h} & -m_{u} / A_{u} \\
A_{h} & A_{u}
\end{array}\right]\left[\begin{array}{c}
\dot{x}_{h}(0) \\
\dot{x}_{u}(0)
\end{array}\right]=\left[\begin{array}{c}
\mathbf{I}_{h e x} / A_{h}-\mathbf{I}_{u e x} / A_{u} \\
0
\end{array}\right]
$$

So the initial endolymph velocity in duct $(h)$ becomes:

$$
\dot{x}_{h}(0)=\frac{\mathbf{I}_{h e x} \cdot A_{u} / A_{h}-\mathbf{I}_{u e x}}{\rho \cdot\left(h \cdot A_{u}+u \cdot A_{h}\right)}
$$

The equation of motion for a single duct circuit is equal to:

$$
\left(M_{h}, \ddot{x}_{h}+F_{h} \cdot \dot{x}_{h}+S_{h} \cdot x_{h}\right) / A_{h}=\left(M_{u} \cdot \ddot{x}_{u}+F_{u} \cdot \dot{x}_{u}\right) / A_{u}
$$

Combination of (3.5.1) with the equation of continuity (lower row of (4.2.1)) gives

$$
M \cdot \ddot{x}_{h}+F \cdot \dot{x}_{h}+S \cdot x_{h}=0 \text {, }
$$

wherein:

$$
\begin{aligned}
M & =\rho \cdot A_{h}^{2} \cdot\left(h / A_{h}+u / A_{u}\right) \\
F & =8 \cdot \pi \cdot \eta \cdot A_{h}^{2} \cdot\left(h / A_{h}^{2}+u / A_{u}^{2}\right) \\
S & =S_{h}
\end{aligned}
$$


The factor $8 . \pi \cdot \eta$ originates from Poiseuille's law; detailed information is given in Muller \& Verhagen (1988).

Simonovitch (1966) presented an analysis based on a single duct circuit, composed of a narrow duct and a wide utriculus. He found that, due to the inertia of the fluid inside the utriculus, the value of $M / F$ is bigger than the values obtained by van Egmond et al. (1949). The detailed discussion by Simonovitch accounts also for different values of $r_{h}$ and is somewhat complicated.

Oman (1980) has developed an equation comparable with eqn (3.5.1) for the non-homogeneous case. The latter equation contains also a third constant (his $-1 / D 1$ ) due to fluid inertia when an acceleration is applied to the duct circuit (in a later paper this constant is, in a slightly different equation equal to $-2 \rho \Lambda$; cf. Oman et al., 1987).

We do not agree with Oman's conclusion that this third constant originates from the presence of a wide utriculus because for the homogeneous equation (i.e. when the angular acceleration $\alpha=0$ ) it disappears. So the third constant is a consequence of the specific input chosen by Oman. It is not a property of the (second order) system itself.

Oman (1980, p. 262) states that: "it is not possible to 'adjust' the two-coefficient van Egmond model differential equation for the effect of different size utricles in various species simply by manipulating the length of the duct segment and calculating a different value of $\Pi$... or by assuming a different value of $\Theta$ ".

In our opinion, the constants $M$ and $F$ (corresponding to $\Theta$ and $\Pi$ ) do contain the influence of a wide utriculus and so influence the time constants of the system itself but the time-dependent behaviour of the system may be modified by choosing a time-dependent input (e.g. Oman's $\alpha(t)$ instead of Van Egmond et al.'s $\gamma$ ). $\dagger$

The equation of Oman accounts also for the ellipticity of a duct. In order to keep our analysis as simple as possible this is not included in our model but can be introduced using Oman's results from the Navier-Stokes equation (e.g. his formula $[14-8])$.

\section{Discussion}

The model presented in this paper provides a new view on both the form and the function of the semicircular ducts. Verification of the predictions of the model, both morphologically and physiologically, is therefore required. We do not have at our disposal specially designed laboratory facilities in which we can obtain such evidence from experiments. However, in the literature we have found some results which can be explained rather well by our theory.

$\dagger$ The homogeneous equation for a single duct is the simplest equation describing the dynamics of the labyrinth. This is only true when prior to $t=0$ the labyrinth has a constant angular velocity. Then the endolymph velocity at $t=0$ is equal to the velocity of the labyrinth. When a constant acceleration is present (prior to $t=0$ ), the motion of the endolymph at $t=0$ is not equal to the motion of the duct, so determination of the initial conditions becomes more complex.

In eqn (19) of Oman et al. (1987), when a delta function is substituted for the acceleration (i.e. $\alpha=\delta(t)$ ) our imaginary cupulometry experiment (cf. section 3.2 ) is established. Then, Oman's eqn (19) becomes (after integration from $t=0-$ to $t=0+$ ) identical with our initial condition. So, Oman's equation is identical to our equation for a single duct when a cupulometry experiment is carried out. 


\subsection{EVIDENCE SUPPORTING OUR MODEL}

\subsubsection{Morphological features (Fig. 1)}

No separations have been found in histological sections of crus commune and utriculus. So, there is no anatomical ground for two or three separate duct circuits in the general labyrinth form. The elastic forces exerted by the cupulae are very small with respect to the forces exerted by the endolymph (except at a very long time after stimulation), so the cupulae cannot be serious barriers to the flow.

Comparing semicircular duct systems of different animals, it is apparent that in many animals the angles between the ducts are not $90^{\circ}$ (Fig. 1). Sometimes there are considerable deviations, e.g. in the labyrinth of Squalus acanthias (a shark) the angle between the anterior and posterior duct is about $115^{\circ}\left(\max\right.$. error $\pm 5^{\circ}$, measured in one labyrinth). The classical theory cannot give a mechanical explanation for the existence of angles other than $90^{\circ}$. Using our theory it can be understood that an obtuse or sharp angle in a particular labyrinth can lead to a better performance of this sense organ because the external impulses in the different ducts may amplify or compensate each other.

\section{TABLE 2}

Angles between semicurcular duct or canal planes of a labyrinth. The angle between anterior and posterior duct is $\alpha^{\prime}$. The angle between anterior and horizontal duct is $\beta^{\prime}$ (angles in degrees). When known, mean values $\pm \mathrm{SD}$. are given. ${ }^{*}=$ angles between canals of bony labyrinth.

\begin{tabular}{lccl}
\hline \multicolumn{1}{c}{ Species } & \multicolumn{1}{c}{$\alpha^{\prime}$} & $\beta^{\prime}$ & \multicolumn{1}{c}{ Reference } \\
\hline guinea pig & $76 \cdot 71 \pm 5 \cdot 5^{*}$ & $122 \cdot 15 \pm 6 \cdot 1^{*}$ & Curthoys et al., 1975 \\
rabbit & $71 \cdot 36 \pm 4 \cdot 4$ & $100 \cdot 64 \pm 9 \cdot 4$ & Mazza \& Winterson, 1984 \\
cat & 90 & 90 & Fernández \& Valentinuzzi, 1968 \\
& $90 \cdot 21 \pm 4 \cdot 1^{*}$ & $89 \cdot 62 \pm 8 \cdot 7^{*}$ & Blanks et al., 1972 \\
rat & 96 & 90 & Fischer, 1980 \\
man & $83-88^{*}$ & $83-85^{*}$ & Beck \& Bader, 1963 \\
& $86 \cdot 16 \pm 4 \cdot 7^{*}$ & $111 \cdot 76 \pm 7 \cdot 6^{*}$ & Blanks et al., 1975 \\
\hline
\end{tabular}

The literature reports a variety of angle measurements between the ducts. A sample of values is listed in Table 2. Some values of $\alpha^{\prime}$ reflect our theoretically determined value of about $73^{\circ}$ surprisingly well. Whatever the functional significance may be, there may be a situation of no flow in at least one of the ducts at a particular rotation.

The value of $73^{\circ}$ is a solution for a special set of parameters of the labyrinth (see eqn (4.1.2.4). In particular, the width of the common duct ( $c$ in this case) influences its value. In our example we have chosen $r_{c}$ equal to the radius of the other ducts. For a rather wide $c$ the angle between the duct planes $\left(\alpha^{\prime}\right)$ will tend to $90^{\circ}$, for a very narrow $c$ this angle must tend to $0^{\circ}$. At the moment we are investigating more closely the influence of other labyrinth parameters (cf. Table 1) on $\alpha^{\prime}$ and on the sensitivity of the various semicircular ducts. To make a well-founded choice of sets of parameters is however not as easy as one would desire. 


\subsubsection{Time constants}

One of the most striking features of our analysis may be the conclusion that there are not two but six time-constants influencing the flow in any peculiar duct of the labyrinth i.e. three long and three short ones. Thus in a cupulometry experiment the long "time constant" measured may be composed of three different real time constants. Therefore we have called the time needed for the endolymph displacement to decay from its peak value to $1 / 10$ of that value, times ${ }^{10} \log (e)$, the "decay constant".
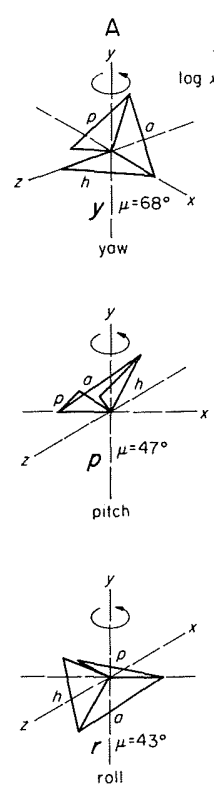

B NARROW U
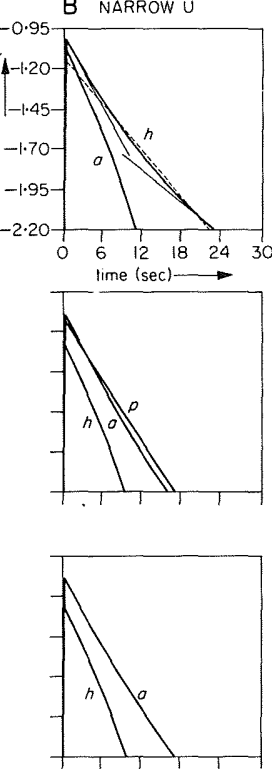

C WIDE U
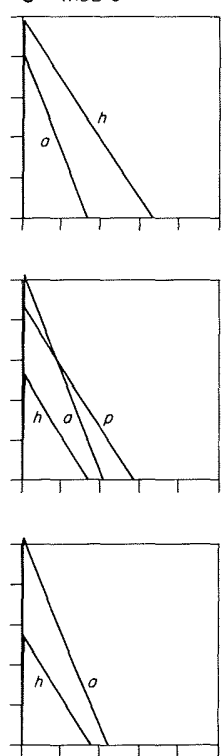

FIG. 12. Simulations with the Runge-Kutta method of endolymph displacement in a "human-like" labyrinth (cf. also Table 3 for numerical information). The geometry is drawn in Fig. 5. The radii of ducts $a, p$ and $h$ are $1.75 \times 10^{-4} \mathrm{~m}, \mathrm{r}_{c}$ is $3.38 \times 10^{-4} \mathrm{~m}$. The angles between the ducts were chosen according to Blanks et al. (1975), so $\alpha=94^{\circ}, \beta=68^{\circ}$ (cf. also Table 2). Rotation prior to $t=0$ takes place about the $y$-axis with $1 \mathrm{rad} / \mathrm{sec}$. The value of $S$ (cupular elasticity) is adjusted to produce a full time scale in the graphs of $30 \mathrm{sec}$. This time scale can be easily changed by a slight variation of $S$; its value is not critical.

Column A: type of rotation. Column B: simulations with relatively narrow utriculus $\left(r_{u}=1.4 \times 10^{-4} \mathrm{~m}\right)$. Column C: simulations with relatively wide utriculus $\left(r_{u}=4 \cdot 24 \times 10^{-4} \mathrm{~m}\right)$. The time constants are the same for each column (cf. Table 3 ). In Table 3 the approximate values of a "decay constant" expressing the total decay in seconds from the peak endolymph displacement about one ${ }^{10} \mathrm{log}$-unit is given for each duct (so this constant is equal to the time in which the endolymph displacement decays to $1 / 10$ of the peak value, times ${ }^{10} \log (e)$ ). Also the maximum excursions of the endolymph in each duct are indicated.

In the rows, the responses to a definite type of rotation (yaw, pitch or roll) are given. Only for pitch (row 2) have we drawn the endolymph displacement curves for the posterior duct $(p)$ because in yaw the endolymph displacement in $(p)$ was very small and in roll the values were negative, due to sign conventions (cf. Muller \& Verhagen, 1988).

The scale of the axes is in all graphs the same. Abcissa: time in seconds, Ordinate: endolymph displacement $(x)$ in metres times $10^{4}$ in ${ }^{10} \log$-units. Abbreviations: see Table 1 and Fig. 1 . This figure is further explained in section 5.1.2. 


\section{TABLE 3}

(cf. also Fig. 12)

A: Parameters, belonging to the simulations of Fig. 12

$r_{a, p, h}=1.75 \times 10^{-4} \mathrm{~m}, r_{\mathrm{c}}=3.38 \times 10^{-4} \mathrm{~m}$.

$S=4 \times 10^{-5} \mathrm{~N} / \mathrm{m}$ in order to obtain a reasonable time scale.

$T$ in seconds, $(e)=$ extrapolated value,

$T_{a}(y)$ means: decay constant for anterior duct in yaw.

Other abbreviations are analogous to this one.

$x_{\max }$ is maximal endolymph displacement in microns.

\begin{tabular}{|c|c|c|c|c|c|c|}
\hline Time constants & \multicolumn{3}{|c|}{ Narrow $u\left(r_{u}=1.4 \times 10^{-4} \mathrm{~m}\right)$} & \multicolumn{3}{|c|}{ Wide $u\left(r_{u}=4.24 \times 10^{-4} \mathrm{~m}\right)$} \\
\hline $\begin{array}{l}T_{1} \\
T_{2} \\
T_{3} \\
T_{4} \\
T_{5} \\
T_{6}\end{array}$ & \multicolumn{3}{|c|}{$\begin{array}{l}7 \cdot 08 \\
19 \cdot 55 \\
5 \cdot 40 \\
5 \cdot 43 \times 10^{-3} \\
4 \cdot 79 \times 10^{-3} \\
3 \cdot 60 \times 10^{-3}\end{array}$} & \multicolumn{3}{|c|}{$\begin{array}{l}7 \cdot 08 \\
6 \cdot 94 \\
4 \cdot 28 \\
6 \cdot 15 \times 10^{-3} \\
5 \cdot 11 \times 10^{-3} \\
4 \cdot 79 \times 10^{-3}\end{array}$} \\
\hline Decay const. & Yaw & Pitch & Roll & Yaw & Pitch & Roll \\
\hline $\begin{array}{l}T_{a} \\
T_{p} \\
T_{h}\end{array}$ & $\frac{4 \cdot 10}{7 \cdot 59}$ & $\begin{array}{l}6 \cdot 08 \\
6 \cdot 82 \\
4 \cdot 21\end{array}$ & $\frac{6 \cdot 51}{4 \cdot 38}$ & $\frac{4 \cdot 17}{6 \cdot 87}$ & $\begin{array}{l}4.15 \\
6.75 \\
6.60(e)\end{array}$ & $\frac{4.36}{6.62(e)}$ \\
\hline \multicolumn{7}{|l|}{ max. excurs. } \\
\hline $\begin{array}{l}x_{a, \max } \\
x_{p, \max } \\
x_{h, \max } \\
\end{array}$ & $\begin{array}{l}8 \cdot 7 \\
0 \cdot 18 \\
9 \cdot 9\end{array}$ & $\begin{array}{l}8 \cdot 3 \\
7 \cdot 6 \\
5 \cdot 6\end{array}$ & $\begin{array}{r}8 \cdot 5 \\
-7 \cdot 7 \\
5 \cdot 8 \\
\end{array}$ & $\begin{array}{c}6 \cdot 9 \\
0 \cdot 08 \\
11 \cdot 1 \\
\end{array}$ & $\begin{array}{r}12 \cdot 5 \\
7 \cdot 8 \\
3 \cdot 0 \\
\end{array}$ & $\begin{array}{r}12 \cdot 7 \\
-7 \cdot 6 \\
3 \cdot 2 \\
\end{array}$ \\
\hline \multicolumn{7}{|l|}{$\begin{array}{c}\text { ratios of } \\
\text { decay const. }\end{array}$} \\
\hline $\begin{array}{l}T_{p}(p) / T_{h}(y) \\
T_{a}(p) / T_{h}(y) \\
T_{a}(r) / T_{h}(y)\end{array}$ & $\begin{array}{l}0.90 \\
0.80 \\
0.86 \\
\end{array}$ & & & $\begin{array}{l}0.98 \\
0.60 \\
0.63 \\
\end{array}$ & & \\
\hline $\begin{array}{l}T_{h}(p) / T_{h}(y) \\
T_{h}(r) / T_{h}(y)\end{array}$ & $\begin{array}{l}0.55 \\
0.58\end{array}$ & & & $\begin{array}{l}0.96 \\
0.96\end{array}$ & & \\
\hline
\end{tabular}

B: Data calculated from Melvill Jones et al. (1964, Table 1).

\begin{tabular}{ccc}
\hline & $\begin{array}{c}\text { sensation } \\
\text { cupulometry }\end{array}$ & $\begin{array}{c}\text { oculomotor } \\
\text { response }\end{array}$ \\
\hline$T(p) / T(y)$ & 0.52 & 0.42 \\
$T(r) / T(y)$ & 0.60 & 0.26 \\
\hline
\end{tabular}


5.1.2.1. Yaw-pitch-roll experiments. Melvill Jones et al. (1964) carried out a series of experiments in which the decay constant was measured in man in yaw, pitch and roll. They reported values of about $10 \cdot 2 \mathrm{sec}$ in yaw, and of $5 \cdot 3$ and $6 \cdot 1 \mathrm{sec}$ in pitch and roll, respectively (sensation cupulometry) and values of 15.6 (yaw), 6.6 (pitch) and $4.0 \mathrm{sec}$ (roll) in the oculomotor response.

With our model, the outcome of these experiments can be reinterpreted. Therefore we have carried out two sets of simulations of endolymph displacement curves with a "human-like" labyrinth: one set with a relatively wide utriculus (following Oman, 1980 ) and the other set with a relatively narrow utriculus (according to arguments put forward by Dohlman, 1980). These simulations are presented in Fig. 12 and Table 3.

With a narrow utriculus the flowpath of the horizontal and the anterior ducts become more strongly coupled, so the endolymph displacement curves will show a more prominent combination of time constants (i.e. a curved shape, see Fig. 12, column b). Table $3 \mathrm{~A}$ shows that the ratios of the decay constants of the different rotation directions vary between 0.55 and 0.90 . This agrees with corresponding values obtained from the data of Melvill Jones et al. (1964; cf. Table 3B). The values from these measurements are however somewhat lower. This is probably due to the incomplete matching between our model and a real human labyrinth (for $\alpha^{\prime} \rightarrow 90^{\circ}$ the above ratios become lower).

For a wide utriculus the horizontal and anterior duct behave more independently. So, a single time constant will dominate in the endolymph displacement curves. The ratios of the decay constants between anterior and horizontal duct are about $0 \cdot 6$, also in agreement with the results of Melvill Jones et al. The above reinterpretation of these experimental results therefore supports our labyrinth model.

Benson \& Bodin (1966) investigated the influence of gravity on post-rotational response in human subjects. They applied a rotation, then suddenly stopped the subject (with $5 \mathrm{rad} / \mathrm{sec}^{2}$ ) as in an ordinary cupulometry experiment. Yet the subject was reoriented in another position. This movement took 2-3 sec. They found striking differences in decay constants both for after-sensation and after-nystagmus. These results can be reinterpreted using our theory as follows.

The decay constant of after-sensation Benson \& Bodin (1966) measured for yaw rotation with a vertical subject was $26.5 \mathrm{sec}$ (their table 1). After reorientation to prone, supine, right side down (RSD) or left side down (LSD) this constant was about $8 \cdot 0-9 \cdot 5 \mathrm{sec}$. During the rather fast reorientation movement the vertical ducts become heavily stimulated. Also the flow in the horizontal duct tends to remain horizontal so part of this flow will enter the vertical ducts. The latter effect is probably rather small compared with the vertical stimulation. According to Fig. 12 shorter time constants will become more prominent in the decay curves (i.e. in the curves for pitch and roll).

Figure 4 of Benson \& Bodin (1966) shows that for movement from vertical to RSD or LSD the decay constants become equally shorter. However a movement from vertical to supine produces a longer decay constant $(9 \cdot 7 \mathrm{sec})$ than a movement to prone $(7 \cdot 1) \mathrm{sec})$. Our theory can explain these data rather well. A movement to RSD or LSD will cause a roll-component of endolymph flow in the vertical ducts. 
Following Ewald's law the anterior as well as the posterior cristae respond to ampullofugal flow. The left and right labyrinth will behave in an (opposite) symmetrical situation for RSD and LSD movements. So, equally shorter decay constants will be more prominent in both situations (see above).

Movements to prone or supine positions will cause a pitch-component of endolymph flow in the vertical ducts. Yet both labyrinths behave in an (equal) asymmetrical way. Movement to supine will cause an ampullofugal flow in ducts $p$ and an ampullopetal flow in ducts $a$. Movement to prone will produce a reverse effect on the flow. The flow situation in prone or supine will be different because the radii of the crus commune and the utriculus differ from each other and from the radii of the ducts. Also, the simultaneously excited anterior or posterior ampullae (following Ewald's law) may cause different decay constants (although this is not a consequence of our model).

The fact that the values of the RSD and LSD decay constants are approximately half-way between the values of the prone and supine decay constants can also be expected because: (1) pitch and roll movements have decay constants of about the same order of magnitude (cf. Table 3); (2) the effect of the different radii of crus commune and utriculus is "added" or "subtracted" from the vertical flow in respectively supine or prone movement.

Also, the results drawn in fig. 6 of Benson \& Bodin can be interpreted with our theory. These effects are, however, less conclusive than in the above cases, so detailed simulations will be required.

5.1.2.2. Decay curves. Figure $12 \mathrm{~B}$ shows that in a labyrinth with a relatively narrow utriculus, several time constants appear in the decay curves of the endolymph displacement. This is especially the case for yaw (Fig. 12B,y: continuous lines).

A "decay-curve" measured by Groen et al. (1952, fig. 3) from isolated fibres of the horizontal duct of the ray (Raja clavata) shows not only the time constant of $40 \mathrm{sec}$ reported by the authors, but also a time constant of about half this value in the very beginning of the curve.

A curve of compensatory eye velocity against time elapsed after suddenly imposing a post-rotational stimulus of $60^{\circ}$ per sec published by Melvill Jones (1965) shows also very clearly two long time constants.

In Fig. 12B,y the dotted line shows how the above authors might have fitted their experimental decay curves (i.e. for duct $h$ ). It is obvious that this line is not a good fit for a time less than ca. 6 sec. So, the above experimental data may be well explained by our theory (under the assumption of a relatively narrow utriculus, cf. sections 5.1.2.1, 5.1.4).

One could question whether the smaller long time constant is due to the dynamics of the afferent neurons (e.g. adaptation and rate-sensitive processes). This is indeed a possibility (but see section 5.1.4).

\subsubsection{Response plane determination}

The present theory implies that in a general case all three cupulae are moved by a flow dividing over the entire duct system. Löwenstein \& Sand (1940) present in 
their table I (p. 96) the responses of the semicircular ducts (i.e. the sense organs in the ampullae) of the thornback ray (Raja clavata) to angular displacements about the three primary axes. $\dagger$

From this table it can be seen that the horizontal ampullae give signals only when rotation about the vertical axis takes place (as expected in the classical theory) but that the vertical ducts (ampullae) respond to any rotation about any of the three primary axes. Thus there is also a response of the vertical ducts when the labyrinth is rotated about a vertical axis.

For a completely aligned labyrinth, i.e. with the vertical duct planes oriented purely perpendicular to the plane of rotation it is, using the classical theory of three single ducts, rather mysterious why there should be a response in the vertical ducts when the labyrinth is turned around a vertical axis. With our theory this behaviour can be understood, at least for the anterior duct (cf. section 4.1). However, because the ray's labyrinth has a highly derived and unusual shape with non-planar ducts and an almost separate posterior duct, a detailed discussion about the flow cannot be given without accurate specification of the geometrical data and rotation directions.

The experiments of Löwenstein (1970) with the labyrinth of the lamprey (Lampetra fluviatilis) have revealed that with this two-duct labyrinth, perception in both the vertical and the horizontal planes is possible. Löwenstein provides a figure in which internal flow inside the ampullae should explain the horizontal response (his fig. 7). Because of the tiny dimensions of the ampulla and the very low Reynolds number, we think it very unlikely that such a flow can occur. Using our theory the vertical ducts together with the utriculus form a circuit which is oblique to the horizontal plane, so rotation in the horizontal plane may produce flow in both ampullae. The complex shape of the cristae in this labyrinth might be an adaptation to enable a distinction between the flow along different duct circuits.

Estes et al. (1975) have investigated responses of the three different ampullae in the cat when the ducts are in (respectively out of) the plane of rotation. They report that the ducts in this animal behave as separate circuits, as in the classical theory. This is, however, not in contradiction to our theory. We do not exclude that for certain special cases the three duct circuits behave rather separately but we also include other possibilities. In the cat the ducts are almost exactly perpendicular to each other (cf. Table 2) and the utriculus in this animal is rather short (as in Fig. 1f). When the utricular space is relatively wide a pressure difference at the junctions of the ducts can hardly be built up, so coupling of duct circuits when they are rotated in plane is not necessary. In such labyrinths coupling can, however, become very important when the head is moved in pitch or roll (see sections 5.2.1, 5.2.3).

\subsubsection{Conclusion}

Although an unequivocally conclusive verification cannot be given, we think we have found enough experimental evidence in the literature to make our theory

\footnotetext{
† From Löwenstein (1970, pp. 425, 426), who refers to the paper of Löwenstein \& Sand (1940), we received the impression that the yawing response of the vertical ampullae discussed here was present in the dogfish (Scyllium) but that in the ray (Raja clavata) this response is absent! Despite this confusing information we have finally assumed that in the (1940) paper the ray was the correct animal.
} 
worthy of further exploration. The interconnection of different labryinth parts follows from the numerous morphological descriptions. Also a large variation in angles between duct planes has been reported in the literature. In our view, a model based on the real shape of the labyrinth (with connected ducts) is more realistic than a hypothetical system of three separate ducts for which no morphological evidence at all is present.

Electrophysiological experiments indicate that the responses of the ampullar sense organs in different directions of rotation are not limited to single duct circuits. Other experiments (see above) seem to confirm that the ducts may operate independently. We do not exclude that possibility. However, even in these labyrinths, coupling of various circuits of endolymph flow may occur for out-plane rotations. The latter fact is well reflected in the yaw-pitch-roll experiments discussed above.

The appearance of several exponential components in some decay curves might partly be ascribed to adaptation and rate-sensitive processes associated with the encoding process. We have shown, however, that a decay curve with more long time constants can be generated by our model, especially when the utricular volume is narrow. This is a controversial point, recently discussed in the literature (Oman, 1980; Dohlman, 1980).

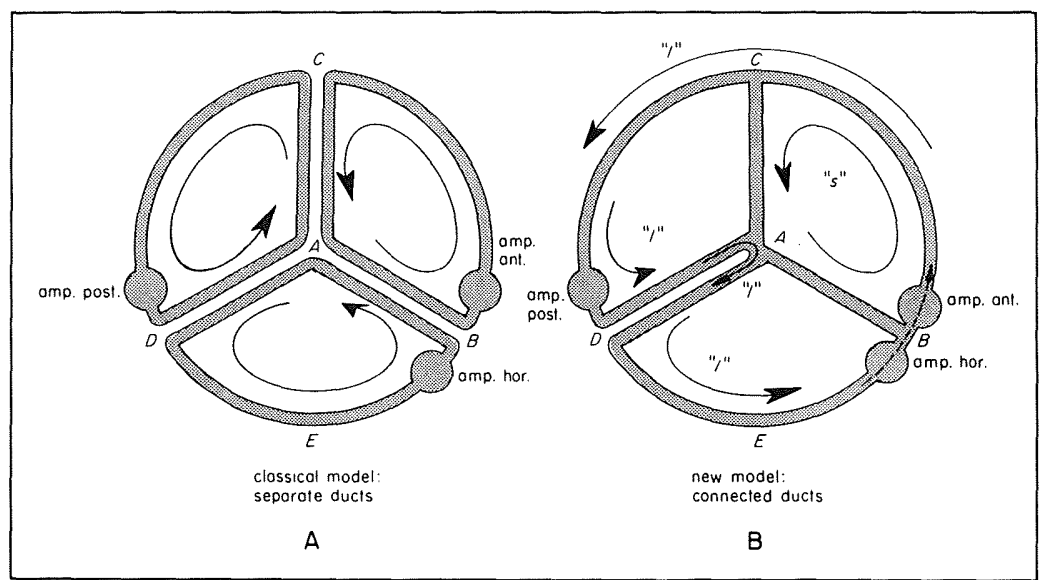

FIG. 13. Examples of labyrinths with duct circuits of equal size positioned perpendicular to each other. The labyrinths are rotated around $A$ in a plane through the peripheral parts of the ducts (about the plane of the paper when one considers the drawings as a projection of the labyrinths). The arrows indicate the flow. (A) Classical model formed by three separate duct circuits. (B) The flow according to our model. The fluid flows along a small " $s "$ path as well as along a large " $l$ " one. This results in six time constants depending on the dimensions of the labyrinth (not the angles between the ducts). The fluid flow in a particular duct depends on these six time constants and also on the angles between the canals and the position of the labyrinth with respect to the rotation vector. This is not the case for labyrinth (A)

When the labyrinth (A) is rotated in the plane of one particular duct no flow occurs in the other ducts. In labyrinth (B) flow then exists in all three ducts. 
5.2. APPLICATIONS OF OUR MODEL VERSUS PREVIOUS VIEWS

\subsubsection{Endolymph flow along different duct circuits (Fig. 13)}

In a general case of the classical view of endolymph flow the fluid flows inside each of the three duct circuits (Fig. 13A). When rotation is limited to the plane of one duct then only flow in this duct occurs. Fig. 13B shows what may happen in the same case following our theory. In this special case there is a "small" flow path ("s"), limited to the anterior duct and a part of the utriculus (i.e. triangle $A B C$ ), but there is also a "large" flow path ("l") in which all three ducts are involved as well as another part of the utriculus (thus along a path $B C D A E B \ldots$...). A variety of different divisions of the flow over the whole circuit is possible depending on different positions and rotations of the labyrinth.

It is questionable whether it is possible to create a situation in which flow is restricted to only one duct when the labyrinth is rotated in the planes of the three ducts, respectively. Therefore, when the labyrinth is rotated in the plane of one of the ducts, flow may also occur in the other two ducts. This flow is caused by pressure differences at the junctions of the ducts. These pressure differences are mainly due to fluid inertia and friction and, on a very long time scale, also due to elastic forces of the cupulae.

Meyer zum Gottesberge \& Maurer (1949) recognized the fact that flow may occur over both vertical ducts. However, they considered this flow to be an addition of the circulations occurring in the two separate ducts (cf. their fig. 1, "Hintereinanderschaltung", and their fig. 2, "Parallelschaltung"). This is an invalid physical representation also leading to incomplete flow pictures e.g. the flow paths along crus commune (their fig. 1) and horizontal duct (their figs 1 and 2) have not been found. They finally come to the conclusion that (p. 705): "Die Strömungen in einzelnen Bogengängen lassen sich annähernd so betrachten als ob jeder Bogengang ein geschlossenes Ringsystem bildet." (etc.).

De Vries (1956) discussed the possibility of interaction of flow between the ducts but did not recognize its importance: "Indeed when the fluid in one duct is propelled by an acceleration, part of it may flow through into another duct. The other ducts are, however, a shunt with a high resistance on the path they have in common, so that the leakage is small. Moreover this effect could easily be taken into account by the computing mechanism of the central nervous system, since it is a linear effect."

Oman et al. (1987, p. 8 , note 1) state: "With a canal oriented so as to maximize its projection (and hence its sensitivity) in the plane of rotation, the other two nearly orthogonal canals will have nearly zero projection area in the plane of rotation, and therefore experience negligible net acceleration pressure. Hence negligible endolymph flow will occur into or out of these entrances to significantly alter the flow in the canal located in the plane of rotation."

Our example 3 (section 4.1.2.3) falsifies this conclusion because flow may also occur in ducts where no external impulse is generated.

\subsubsection{Biophysical characteristics}

Valentinuzzi (1967) gave a mathematical treatment of accelerations and forces inside a labyrinth system. Although valuable and interesting, his results are limited 
to a single fluid ring and not to the complex duct system formed by the entire labyrinth. Thus for this latter configuration his calculations have to be modified i.e. extra forces occur in a peculiar duct due to acceleration of the fluid in other ducts.

Since Fernández \& Valentinuzzi (1968) several authors (e.g. Ramprashad et al., 1986) have calculated the "biophysical characteristics" (e.g. time constants) of the semicircular ducts from morphological measurements. These calculations are valid for single circuits but have to be reviewed when our theory is followed.

\subsubsection{Time constants}

Jones \& Spells (1963) discuss an adjustment of time constants by changing the factor $R^{2} / r^{2}$ in which $R$ is the radius of the duct ring and $r$ the radius of the duct itself. Using our concept, is is also possible to adjust the time constants of the entire labyrinth to a certain range of values by changing the lengths and the cross-sectional areas of other parts of the labyrinth. As it seems reasonable to expect that the wide array of forms of the labyrinth in all 40000 species of vertebrates is related to its functional properties, this new theory opens a way to a functional explanation of this form diversity. Also, the three cupulae may have a varying mechanical influence on the flow on a relatively long time scale, so the elastic properties of one, two or three cupulae may be involved in the balance of forces. This has profound consequences for the long time constants of the system.

\subsubsection{Sensitivity}

Ten Kate et al. (1970) define the sensitivity of a single duct circuit as the displacement of fluid in the narrow part of the duct per stimulus velocity unit, times the ratio of the cross-sectional area of duct and ampulla $\left(A_{c a n} / A_{a m p}\right)$. In formula form:

$$
G=\frac{A_{C}}{4 \cdot \pi \cdot \nu \cdot l_{1}} \cdot \frac{A_{c a n}^{2}}{A_{a m p}} \quad(\text { after ten Kate } \text { et al., 1970) }
$$

in which $A_{C}$ is the area enclosed by the duct circuit, $\nu$ is the kinematic viscosity of endolymph, and $l_{1}$ is the length of the narrow part of the duct. Although this formula adequately describes the sensitivity for a single duct circuit it needs modification when our theory is applied.

In this respect it is interesting that both the crus commune and the utriculus have mostly bigger (external) cross-sectional areas than the ducts. Thus it appears that in evolution the parts of the labyrinth wherein no cupulae are present, and thus no sensitivity is required, have become more voluminous, possibly increasing the sensitivity of the semicircular ducts. This view is in fact a confirmation and elaboration of earlier ideas formulated by Simonovitch (1966), Van Buskirk (1977) and Oman (1980). Dohlman (1980), however, suggested that the utriculus is for the greater part filled with a gelatinous matter, not contributing to flow. The gelatinefilling of the utriculus might be a prevention of internal circulation in this (sometimes) wide part of the labyrinth (cf. Muller \& Verhagen, 1988).

Our results concerning angles between duct planes (section 5.1.1) and time constants (section 5.1.2) support the viewpoint of a narrow utriculus, which also seems to be experimentally verified by dye-injection experiments (cf. Dohlman, 
1980, pp. 17, 18). However, we think the arguments of Oman \& Van Buskirk in favour of a wide utriculus are also relevant and attractive. To our knowledge there is no report of the occurrence of a gelatinous matter inside the crus commune. In our opinion the above controversial results need further attention.

The widening of the duct into the ampulla might, at first glance, be in contradiction to some of the above arguments. However, according to Dohlman (1980), the ampulla is for the greater part filled with a gelatine-like matter, embedding the cupula at its distal end. Also, the cupula itself and the bulge of sensory epithelium have a considerable volume. Thus the net volume of endolymph fluid inside the ampulla will probably be of the same order of magnitude as that of a duct segment of comparable length.

Considering the labyrinth as a whole, an increase of its sensitivity can be obtained by enlarging the lengths of the ducts or by increasing the cross-sectional area of some ducts (including crus commune and utriculus). Obviously any change of the size of the ducts results in a change of all six time constants (cf. section 3.5).

\subsubsection{The torsion pendulum theory}

The current torsion pendulum theory, treating the flow in a single duct circuit, is expressed in terms of quantities related to rotation, viz. angular velocities, moments of inertia, frictional moment of fluid and elastic moment of the cupula (cf. e.g. van Egmond et al., 1949). In this paper we chose for an approach with (curvi-)linear velocities of endolymph along the ducts, masses of fluid etc. The question might arise whether it is favourable to transform our notation also to a notation concerning rotational motion. In fact the torsion pendulum theory is a very special case of our approach. We arrived however at the conclusion that a "torsion pendulum representation" of our theory would unnecessarily complicate the formulas. We consider for a single duct circuit with a uniform diameter the torsion pendulum notation as very elegant but for our combined circuit extending in a $3 \mathrm{D}$-space it loses much of its charm.

We agree with Oman et al. (1987) that, also for a single duct circuit, "torsion pendulum" is an inappropriate characterization because the endolymph fluid does not behave as a rigid structure.

We would like to thank especially the director of the Department of Experimental Animal Morphology and Cell Biology, Professor Dr J. W. M. Osse, for making available all laboratory facilities for this project, which has not been a part of current research. He is also acknowledged for critical comments on the manuscript.

Mrs A. L. Hana typed a part of this paper. Finally we wish to thank an anonymous referee for careful reading of the manuscript and many useful comments.

\section{REFERENCES}

BECK, C. \& BADER, J. (1963). Ein Beitrag zur feineren Anatomie des Menschlichen Innenohres. Archiv. Ohren-u sw. Heilk. u. Z. Hals usw. Heilk. 181, 245-267.

BENSON, A. J. \& BoDIN, M. A. (1966). Comparison of the effect of the direction of the gravitational acceleration on post-rotational responses in yaw, pitch and roll. Aerospace Medicine 37, 889-897.

Blanks, R. H. I., Curthoys, I. S. \& MARKsham, C. H. (1972). Planar relationships of semicircular canals in the cat. Am. J. Physiol. 223, 55-62. 
Blanks, R. H. I., Curthoys, I. S. \& MARKham, C. H. (1975). Planar relationships of the semicircular canals in man. Acta Otolaryngol. 80, 185-196.

BuRlet, H. M. de (1931-1939). Vergleichende Anatomie des Stato-akustischen Organs. in BoLK L. et al., eds, Handbuch der vergleichenden Anatomie der Wirbeltiere. Vol. II-2. Berlin and Vienna: Urban and Schwartzenberg. pp. 1293-1380.

Burlet, H. M. DE \& Versteegh, C. (1930). Über Bau and Funktion des Petromyzon labyrinthes. Acta oto-laryng. Suppl. 13, 5-58.

Curthoys, I. S., Curthoys, E. J., Blanks, R. H. I. \& Markham, C. H. (1975). The orientation of the semicircular canals in the guinea pig. Acta Otolaryngol. 80, 197-205.

Dohlman, G. F. (1980). Critical review of the concept of cupula functions. Acta Otolaryng. (Stockholm) suppl. 376, 3-30.

Egmond, A. A. J. van, Groen, J. J. \& Jongkees, L. B. W. (1948). The turning test with small regulable stimuli. I. J. Laryng. and Otol. 62, 63-69.

Egmond, A. A. J. van, Groen, J. J. \& Jongkees L. B. W. (1949). The mechanics of the semicircular canal. J. Physiol. 110, 1-17.

Egmond, A. A. J. van, Groen, J. J. \& Jongkees, L. B. W. (1952). The function of the vestibular organ. Pract. Oto-rhino-laryng. Suppl. 2 ad. Vol. XIV, pp. 1-109.

Estes, M. S., Blanks, R. H. I \& MARKhaM, C. H. (1975). Physiologic characteristics of vestibular first-order canal neurons in the cat. I. Response plane determination and resting discharge characteristics. J. Neurophysiol. 38, 1232-1249.

FERnÁndez, C. \& VAlEntinuzzi, M. (1968). A study on the biophysical characteristics of the cat labyrinth. Acta Otolaryng. 65, 293-310.

FisCHER, A. J. E. M. (1980). The vestibular system of the manganese-deficient rat. Thesis. Katholieke Universiteit Nijmegen, The Netherlands.

GRANT, J. W. \& VAN BUSKIRK, W. C. (1976). Experimental measurement of the stiffness of the cupula. Biophys. J. 16, 669-678.

Gray, A. A. (1907). The Labyrinth of Animals including Mammals, Birds, Reptiles and Amphibians. Vols. I, II. London: Churchill.

GRAY, O. (1951). An introduction to the study of the comparative anatomy of the labyrinth. J. Laryng. and Otol. 65, 681-703.

GrAY, O. (1955). A brief survey of the phylogenesis of the labyrinth. J. Laryng. Otol. 69, 151-179.

Groen, J. J. \& JongkeEs, L. B. W. (1948). The turning test with small regulable stimuli III and IV. J. Laryng. Otol. 62, 231-240.

Groen, J. J., LÖWENSTEIN, O. \& VENDRIK, A. J. H. (1952). The mechanical analysis of the responses from the end-organs of the horizontal semicircular canal in the isolated elasmobranch labyrinth. $J$. Physiol. 117, 329-346.

HulK, J. \& JONGKeES, L. B. W. (1948). The turning test with small regulable stimuli. II. J. Laryng. Otol. 62, 70-75.

Jones, G. M. \& Spells, K. E. (1963). A theoretical and comparative study of the functional dependence of the semicircular canal upon its physical dimensions, Proc. Royal. Soc. London B 157, 403-419.

KATE, J. H. TEN (1969). The oculo-vestibular reflex of the growing pike. A biophysical study. Thesis. Rijksuniversiteit, Groningen, the Netherlands.

KATE, J. H. TEN, BARneveld, J. H. VAN \& Kuiper, J. W. (1970). The dimensions and sensitivities of semicircular canals. J. Exp. Biol. 53, 501-514.

Kuipers, L. \& Timman, R. (eds) (1966). Handboek der wiskunde. I. Amsterdam, The Netherlands: Scheltema and Holkema NV (in Dutch).

LÖWENSTEIN, O. (1970). The electrophysiological study of the responses of the isolated labyrinth of the lamprey (Lampetra fluviatilis) to angular acceleration, tilting and mechanical vibration. Proc. Roy. Soc. Lond. B 174, 419-434.

LÖWENSTEIN, O. \& SAND, A. (1940). The individual and integrated activity of the semicircular canals of the elasmobranch labyrinth. J. Physiol. 99, 89-101.

Löwenstein, O., Osborne, M. P. \& Thornhill, R. A. (1968). The anatomy and ultrastructure of the labyrinth of the lamprey (Lampetra fluviatilis L.). Proc. Roy. Soc. Lond. B170, 113-134.

MAYNE, R. (1950). The dynamic characteristics of the semicurcular canals. J. Comp. and Physiol. Psychol. 43, 304-319.

MazzA, D. \& Winterson, B. J. (1984). Semicircular canal orientation in the adult resting rabbit. Acta Otolaryngol. (Stockholm) 98, 472-480.

MELVILL JONES, G. (1965). The vestibular contribution to stabilization of the retinal image. In: The Role of the Vestibular System in the Exploration of Space. NASA SP-77. Washington, DC: US. Government Printing Office. pp. 163-172. 
MELVill Jones, G., BARRY, W. \& KowAlski, N. (1964). Dynamics of the semicircular canals compared in yaw, pitch and roll. Aerospace Medicine 35, 984-989.

Melvill Jones, G. \& Milsum, J. H. (1971). Frequency response analysis of central vestibular unit activity resulting from rotational stimulation of the semicircular canals. J. Physiol. 219, 191-215.

Meyer zum Gottesberge, A. \& MAurer, W. (1949). Uber den Funktionsmechanismus des vertikalen Bogengängenssytems bei der entstehung des Rotatorisches und vertikalen Nystagmus. Arch. Ohr. Nas. Kehlk. Heilk. 155, 705-725.

Muller, M. \& Verhagen, J. H. G. (1988). A mathematical approach enabling the calculation of total endolymph flow in the semicircular ducts. J. theor. Biol. 44, 503-529.

OMAN, C. M. (1980). The influence of duct and utricular morphology in semicircular canal response. In: Vestibular Function and Morphology. (ed. T. Gualtierotti). New York: Springer, Chapter 14.

OMAN, C. M. \& YOUNG, L. R. (1972). The physiological range of pressure difference and cupula deflections in the human semicircular canal. Acta Otolaryng. 74, 324-331.

OMAN, C. M., MARCus, E. M.\& CuRThoys, I. S. (1987). The influence of semicircular canal morphology on endolymph flow dynamics. Acta Otolaryngol. (Stockholm) 103, 1-13.

Ramprashad, F., LANDOlt, J. P., MONey, K. E. \& LAufER, R. (1986). Comparative morphometric study of the vestibular system of the Vertebrata: Reptilia, Aves, Amphibia and Pisces. Uppsala, Sweden: Almquist and Wicksell Tryckeri. pp. 1-42.

Retzius, G. (1881-1884). Das Gehörorgan der Wirbeltiere. Morphologisch histologische Studien. Vols. I and II. Stockholm: Samson and Wallin.

SimonovitCH, M. (1966). Les conditions de mouvement de l'endolymphe à l'intérieur des canaux semi-circulaires. J.F.O.R.L. XV, 1, 45-52.

STEER, R. (1967). The influence of angular and linear acceleration and thermal stimulation on the human semicircular canal. DSc Thesis. Massachusetts Institute of Technology, Cambridge, Massachusetts.

VAlentinuzZI, M. (1967). An analysis of the mechanical forces in each semicircular canal of the cat under single and combined rotations. Bull. Math. Biophys. 29, 267-289.

VAN Buskirk, W. C. (1977). The effect of the utricle on fluid flow in the semicircular canals. Ann. Biomed. Engin. 5, 1-11.

VRIES, H. L. DE (1956). Physical aspects of the sense organs. Progress in Biophysics 6, 208-264.

Werner, Cl. F. (1960). Das Gehörorgan der Wirbeltiere und des Menschen. Leipzig: Georg Thieme.

Wilson, V. J. \& Melvill Jones, G. (1979). Mammalian vestibular physiology. New York: Plenum Press.

\section{APPENDIX}

\section{Symbols}

A point, connecting ducts, $c, u, p_{2}$ and $h_{1}$; cross-sectional area of duct (eventually with subscripts)

$[A]$ term in matrix of equation of motion (idem: $[B],[C]$ ) with index 1-3.

$A_{C} \quad$ area enclosed by duct (section 5.2.4)

a anterior duct

$a_{1}-a_{6}$ constants in terms of velocity in ducts (idem: $b_{i}, c_{i}(i=1,6)$ )

$B \quad$ point, connecting ducts $u, a$ and $h_{2}$

$C \quad$ point, connecting ducts $a, c$ and $p_{1}$

c crus commune

$D \quad$ point, connecting ducts $p_{1}$ and $p_{2}$

$D$ differential operator of Cauchy

$E \quad$ point, connecting ducts $h_{1}$ and $h_{2}$

$F \quad$ coefficient of friction

$G \quad$ sensitivity of semicircular duct (section 5.2.4)

$\mathbf{h}_{s} \quad$ distance from $M$ to line $l_{s}$

$h \quad$ horizontal duct 


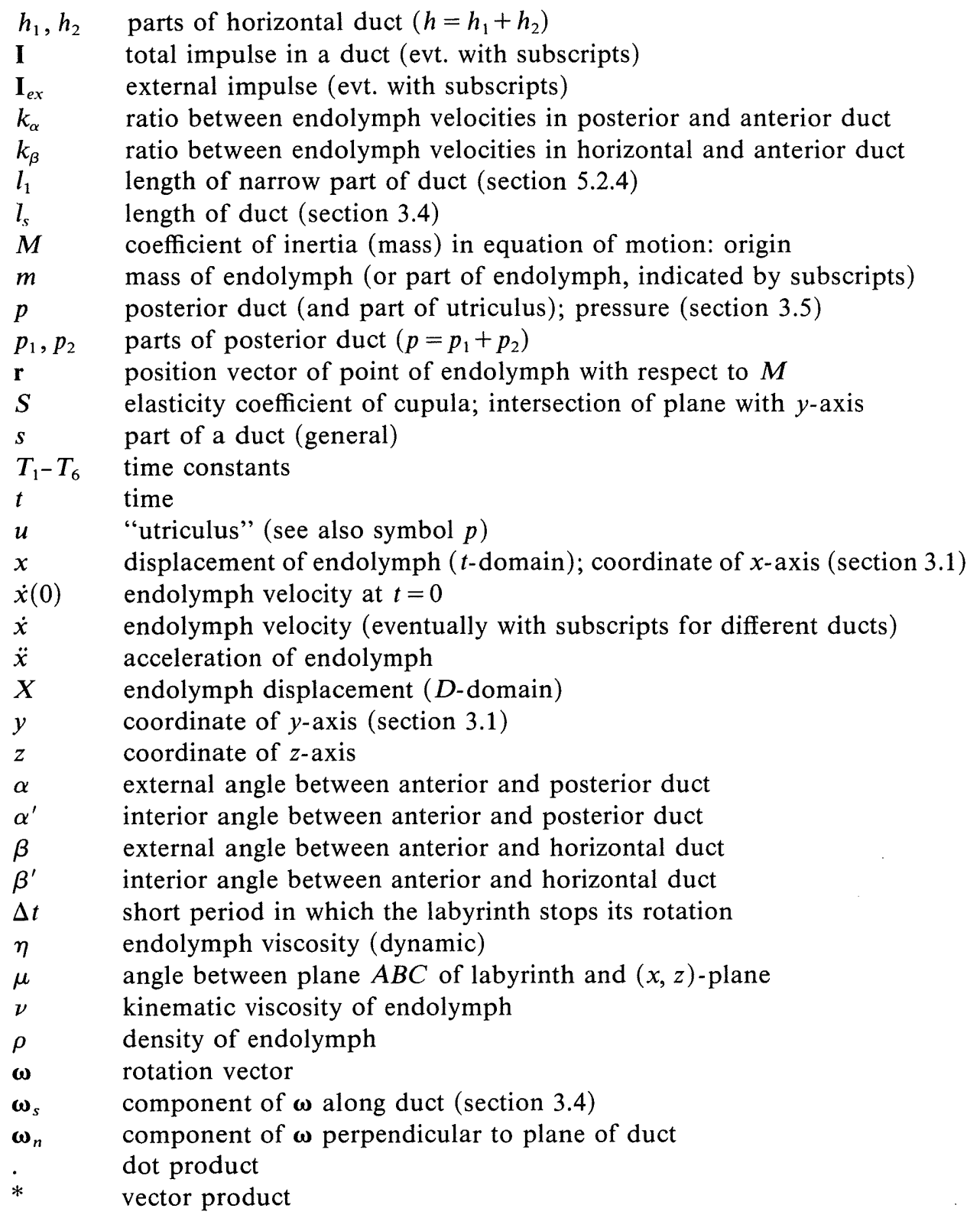

